\title{
Comparative Analysis of Web of Science and Scopus on the Energy Efficiency and Climate Impact of Buildings
}

\author{
Luisa F. Cabeza ${ }^{1, *(\mathbb{C},}$, Marta Chàfer ${ }^{1,2} \mathbb{D}$ and Érika Mata ${ }^{3}$ \\ 1 GREiA Research Group, Universitat de Lleida, 25001 Lleida, Spain; marta.chafer@diei.udl.cat \\ 2 CIRIAF-Interuniversity Research Centre, University of Perugia, Via G. Duranti 67, 06125 Perugia, Italy \\ 3 IVL Swedish Environmental Research Institute, 41133 Gothenburg, Sweden; erika.mata@ivl.se \\ * Correspondence: lcabeza@diei.udl.cat; Tel.: +34-973003576
}

Received: 25 September 2019; Accepted: 9 January 2020; Published: 14 January 2020

\begin{abstract}
Although the body of scientific publications on energy efficiency and climate mitigation from buildings has been growing quickly in recent years, very few previous bibliometric analysis studies exist that analyze the literature in terms of specific content (trends or options for zero-energy buildings) or coverage of different scientific databases. We evaluate the scientific literature published since January 2013 concerning alternative methods for improving the energy efficiency and mitigating climate impacts from buildings. We quantify and describe the literature through a bibliometric approach, comparing the databases Web of Science (WoS) and Scopus. A total of 19,416 (Scopus) and 17,468 (WoS) publications are analyzed, with only $11 \%$ common documents. The literature has grown steadily during this time period, with a peak in the year 2017. Most of the publications are in English, in the area of Engineering and Energy Fuels, and from institutions from China and the USA. Strong links are observed between the most published authors and institutions worldwide. An analysis of keywords reveals that most of research focuses on technologies for heating, ventilation, and air-conditioning, phase change materials, as well as information and communication technologies. A significantly smaller segment of the literature takes a broader perspective (greenhouse gas emissions, life cycle, and sustainable development), investigating implementation issues (policies and costs) or renewable energy (solar). Knowledge gaps are detected in the areas of behavioral changes, the circular economy, and some renewable energy sources (geothermal, biomass, small wind). We conclude that (i) the contents of WoS and Scopus are radically different in the studied fields; (ii) research seems to focus on technological aspects; and (iii) there are weak links between research on energy and on climate mitigation and sustainability, the latter themes being misrepresented in the literature. These conclusions should be validated with further analyses of the documents identified in this study. We recommend that future research focuses on filling the above identified gaps, assessing the contents of several scientific databases, and extending energy analyses to their effects in terms of mitigation potentials.
\end{abstract}

Keywords: bibliometric analysis; energy efficiency of buildings; climate change mitigation; technology; Web of Science; Scopus

\section{Introduction}

The IPCC 5th Assessment Report (AR5) chapter "Buildings" presented the technological options, design practices, and behavioral changes that can lead to large reductions in energy used by buildings [1]. Since the publication of AR5, i.e., in the last 5 years, the body of scientific publications has been growing quickly. In fact, for the next Assessment Report (AR6), 300,000 new publications are expected 
to be covered by the Web of Science (WoS) alone [2]. Performing systematic review work is crucial as selection bias in scientific assessment is becoming a growing concern [3-5].

Bibliometrics (also called scientometrics) is the branch of bibliology that studies the scientific production contained in various types of documents through statistical methods (quantitative analysis of publications). Bibliometrics is considered one of the key research tools. It extends to all scientific areas and is frequently used to evaluate the results of peer-reviewed research and is particularly applicable to fields with large bodies of literature that are difficult to summarize by traditional review methods [6-8]. Bibliometric techniques can be applied to many other inputs, outputs, processes, and artifacts associated with the conduct of science [9]. Research metrics can provide crucial information that would be difficult to gather or understand by means of individual expertise [9].

Most bibliometric analyses use data from the same sources: Thomson Reuters' WoS and Elsevier's Scopus. WoS was the sole tool for citations analysis until the creation of Scopus and Google Scholar in $2004[9,10]$. However, the lack of quality control in Google Scholar raises questions about its suitability as a bibliometric tool [11]. Thus, WoS and Scopus remain today the main sources for citation data [12]. According to Chadegani et al. (2013) [12], WoS includes above 10,000 journals (although some webpages state more coverage). It comprises seven different citation databases including journals, conferences, reports, books, and book series. On the other hand, Scopus contains more than 20,000 peer-reviewed journals from 5000 publishers, together with 1200 open access journals, over 600 trade publications, 500 conference proceedings, and 360 book series from all areas of science. It covers more than 49 million records including trade publications, open access journals, and book series [12,13]. Viera and Gomes 2009 [14] affirmed in their study that Scopus covers a broader range of topics when it comes to journals, but it is limited to more recent publications compared with WoS.

The results of bibliometric analyses may vary depending on the database used. Some studies show that the content of both databases is very similar [15]; however, other studies show that the content of the databases has evolved [16-19]. For instance, Mogeon [16] compared these databases with regard to different disciplines and found that, even though the areas of Natural Sciences and Engineering were the most similar between the databases (with Scopus covering 38\% of the journals and WoS 33\%), the coverage in both databases was unbalanced between countries and languages and that this may introduce some bias when performing comparative analyses. Moreover, Jacso [17] and Falagas et al. [18] compared these databases and confirmed that Scopus covers more journals and its analysis of citations is faster than WoS. However, WoS citation analysis provides more understandable graphics and is more detailed than the Scopus citation analysis [14]. These comparative studies of WoS and Scopus concluded that these two databases are always improving.

Very few previous bibliometric analysis studies were related to energy and none of them focused on trends or analyzed specific options for zero-energy buildings. Using Scopus, Wuni et al. [20] studied global research trends on green buildings in construction journals from 1992 to 2018, and Perea-Moreno et al. analyzed research trends worldwide in the field of urban generation of renewable energy during the period 1977-2017 [21]. De la Cruz-Lovera et al. [22] studied the worldwide research on energy efficiency and sustainability in public buildings, also performed a bibliometric analysis of the literature about energy savings published from 1939 to 2018 [23]. Using WoS, Morkūnaite et al. [24] performed a bibliometric analysis limited to heritage buildings, Zhao et al. [25] studied green buildings constructed during the period 2000-2016, Triani et al. [26] studied the energy efficiency of buildings during the period 2008-2016, and Camarasa et al. [27] studied the diffusion of energy efficiency technologies in European residential buildings during the period 2008-2018. Díaz-Lopez et al. [28] studied the evolution of sustainable building assessment methods with both WoS and Scopus, without comparing the content of the databases. In 2019, Uribe-Toril et al. [19] reviewed the international research on the interactions between the Economy, Energy, and Environment (3E) in the 21st century.

In this study, we quantify and describe, for the first time, recent literature on energy efficiency and climate change mitigation from buildings, at the same time assessing the content of the two main scientific databases in this research field. 


\section{Aim and Scope}

The purpose of this study is to evaluate the literature on energy efficiency and climate change mitigation from buildings since the publication of the IPCC 5th Assessment Report in 2013. More particularly, the objectives of this study are as follows:

- To identify knowledge gluts, in terms of relevant authors, institutes, and geographical distributions.

- To identify research trends and gaps, in terms of keywords and research fields.

- To assess the use of the WoS and Scopus databases for this research field, in terms of content, advantages, and disadvantages.

\section{Materials and Methods}

A search query, trying to include all topics usually enclosed in the "Buildings" chapter of any IPCC Assessment Report, was defined and run in the WoS and Scopus databases. The query consisted of the following strings:

- To capture topics related to buildings and type of buildings: ("hous" OR "building*" OR "residence*" OR "dwelling*" OR "home*" OR domestic OR tertiary OR commercial OR hotel OR "educati*" OR "school*" OR "sport*" OR “service*" OR facility) near/3 ("building*" OR "stock*" OR "sector"

- To capture topics related to energy use/savings and climate change mitigation: (climate OR "emission*" OR "CO2" OR "GHG" OR "mitigat*" OR energy) near/3 (potential OR "mitigat" OR "consum*" OR use OR "sav");

- To capture technologies and other related issues: heating OR cooling OR "thermal comfort" OR "air condition*" OR thermostat OR "HVAC" OR boiler OR insulation OR ventilation OR lighting OR "appliance*" OR "refrigerat ${ }^{* \prime}$ OR cooking OR "electrical device*" OR "energy service ${ }^{*}$ " OR electricity OR affordability OR "energy poverty" OR access OR "fuel poverty" OR "energy inequality" OR "energy service deprivation" OR "basic energy need" OR "satisf*" OR rebound OR "cheap energy" OR "higher use" OR "increased energy use" OR "trend" OR driver OR population OR "specific energy" OR income OR ownership OR penetration OR "floor area" OR "building typ*" OR "technolog*" OR "passive house" OR storage OR green OR materials OR renovation OR retrofit OR efficiency OR "building shell" OR "smart building" OR "ICT" OR "information communication" OR "IOT" OR "internet of things" OR "non-technolog*" OR consumption OR "behavior*" OR lifestyle OR sufficiency OR rebound OR satisfaction OR social OR cultural OR "cost-efficiency" OR sensitivity OR robust OR "econom*" OR feasibility OR global OR region OR world OR "adapt" OR "synerg*" OR "extreme event" OR "damage*" OR reconstruction OR "sustainable development" OR risk OR co-benefit OR trade-off OR spill-over OR "barrier" acceptance OR political OR "policy instrument" OR finance OR "business model*" OR "nation*" OR "region*" OR local.

The first search found 31,850 documents in WoS and 218,358 documents in Scopus. Given the high amount of publications found that were not related to the topic of study, intensive work was carried out at title and abstract levels to find the needed exclusions to avoid such documents. The exclusions used were as follows:

- Related to business: "foreign trade" OR "export intensity" OR "firm performance" OR "bilateral trade" OR "trade balance" OR "corporate reputation*" OR in-house OR "business performance" OR "company performance*" OR "organizational conduct" OR "managerial innovation" OR "consumer satisfaction" OR "consulting services" OR "coach" OR "launch" OR "hous* developer" OR "hous* pric" OR "hous* market" OR "hous* tenure" OR "tenure choice*" OR "property taxation" OR "tax base*" OR "financial sector*" OR "financial development" OR "fiscal reform*" OR banking OR "foreign aid*" OR "political economy" OR "political development" OR 
"world-economy" OR "born global*" OR legitimacy OR "real state" OR "stock exchange ${ }^{* \prime}$ OR "national pension" OR "national facility" OR productivity OR “cognitive habilit*” OR "nois*" OR absenteeism OR "work environment" OR "work engagement";

- Related to computer science: "remote sense" OR "3D model" OR cybersecurity OR "internet filter*" OR "applications server*" OR "learning algorithm*" OR "non-linear" OR randomness OR "frequency modulat" OR "cyber physical system*" OR blockchain OR "software defined network" OR "attack";

- Related to earth sciences: "agricultur" ${ }^{* \prime}$ OR "farmer" ${ }^{*}$ OR "livestock*" OR "vegetable oil ${ }^{* \prime}$ OR "palm oil" OR "soil" OR "porcine*" OR "maize field*" OR "fruit" OR citrus OR "bushfire*" OR "bovine*" OR "animal welfare" OR "grassland management" OR "grazing practic" OR "grassland degradation" ${ }^{*}$ OR "cow*" OR dairy OR poultry OR bat OR food OR "land use" OR biodiversity OR "sand weather*" OR "dust weather*" OR "acid rain" OR "wildfire*" OR "astrophysic*" OR "geolog*" OR seismic OR "earthquake*" OR "volcan*" OR "erupt*" OR "mineral" risk" OR "sea-level rise" OR "coastal adaptation" OR "disaster management";

- Related to education: "teach" OR pupil OR "education policy" OR "school dropout" OR student OR educator OR "medical education";

- Related to health: nursing OR morbidity OR malnutrition OR "medical rehabilitation" OR medicare OR "health insurance" OR "health policy" OR "disease" OR obesity OR disability OR "cell* OR "health risk" OR "drug*" OR "pharmacist*” OR “desinfection*" OR memory OR "health status" OR trauma OR "psychological distress*" OR "biological control*" OR "oncol*" OR "medicin" OR metaproteomic OR keratitis OR "heart valv*" OR "HIV" OR hypoxia OR "hand hygien*" OR "fungal communit" OR "AIDS" OR virus OR veterinary OR lethal OR "medical-care" OR "infection" OR "utism OR “disorder" "food safety" OR "food contamination" OR "biomedic" medicine" OR arthroscopy OR "therapeutic*" OR clinical OR "long-term-care" OR "long-term care" OR "patient" ${ }^{*}$ OR "health care" OR "autogenous shrinkage" OR "health service" OR injury OR caregiver OR "emergency department" OR “adolescent" OR "TMD" OR “TMD-M" OR "personal metabolism*" OR "self-compassion" OR “child support" OR "sexual behavior*” OR "physiotherap*" OR "mental health" OR "adolescent functioning" OR “collective imagin*" OR "climate fiction*" OR cognitive OR phonological OR psychotic OR psycosis OR psychiatry OR "workplace sociology" OR "protective role" OR "feeling*" OR "social support" OR divorce;

- Related to industry: engin" OR "manufact*" OR “textile*" OR "large-scale manufactur" OR crystalline OR "cadmium telluride" OR ethylene OR "vinyl acetate" OR "deflection*" OR "modular system*" OR "production phase ${ }^{*}$ " OR "industrial structur*" OR "pillar industr*" OR "ionic*" OR "total ionizing dose" $\mathrm{OR}^{*}$ "steelmak" OR electrocatalysis OR "pipe spool" OR "wind turbine" OR production OR brand OR "mother brand" OR "power sector" OR "infrastructure plan*" OR "nuclear reaction*" OR "isotop" OR "interfuel substitution" OR "infrastructural project" OR "transmission network" OR "in-vessel retention*" OR "industrial energy efficienc" OR "power industr*" OR hydrogen OR "fuel cell*” OR "nuclear energy" OR “tourism demand" "overnight stay*" OR "short stay accommodation*" OR "tourism econom*" OR "hotel price" OR "public entertainment business-person";

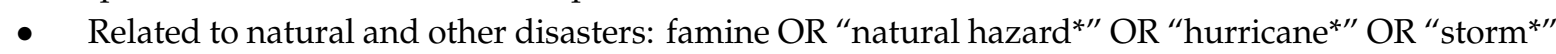
OR "weather correlation*" OR "seawall" OR "dry period*" OR "drought" OR "terroris" OR "hostage*" OR "space weapon*" OR violence OR explosion;

- Related to transport: (fleet OR gasoline OR transportation OR "bicycle network" OR "transport mode" OR "commut" OR rail OR "logistic*" OR "truck" OR "road design" OR "automotive sector*" OR vehicular OR "vehicle" OR "car driver" OR "aircraft operation*" OR "air transport demand" OR "traffic scenario" 
- Related to water: aquaculture OR "fish" OR marine OR "drink" OR "underground water" OR "water treatment" OR desalination OR "aquatic*" OR "flood" "groundwater" OR "flood risk management" OR "greywater" OR "aquatic area" OR "wetland" OR wastewater OR "water loss" OR "water security" OR "water allocation*" OR "water resource*" OR "water environment";

- Others: "radioactiv*" OR "aerodynamic*" OR "satellite power system*" OR "antenn*" OR "microwav" OR "radio sound" " OR "science policy" OR "weathercast" OR "religious theory" OR "limited edition" OR "limited edition product" OR "original* value" OR similarity OR message.

Indices and statistical indicators were then extracted from both databases. The publications were assessed based on the type of publication, language, distribution of publications per year, distribution by country and institute per year, authors, subject area, and journals, as well as keywords used.

Correlations between authors and keywords were analyzed with the bibliometric analysis software VOSviewer [29]. VOSviewer is a freely available software for generating bibliometric maps of scientific fields, showing its versatility (i.e., food chemistry [30], artificial intelligence [31], health [32], social sciences [33], and neuroscience [34]). VOSviewer implements the visualization of similarities mapping technique [35], where networks are drawn in which the distances between nodes show the levels of closeness between them. This technique allows for analysis of the similarities between articles in terms of co-authorship; co-occurrence of keywords in the titles, abstracts, and keywords; and co-citation of common references used in the articles [36]. VOSviewer is especially useful for displaying bibliometric maps that contain maps of at least 100 items in an easily understandable way [29].

\section{Results}

\subsection{Quantitative Description of the Field}

The initial query without the exclusion keywords gave 31,850 documents in WoS and 218,358 in Scopus. After using the listed exclusion keywords, the query resulted in 17,468 documents in WoS and 19,416 in Scopus, of which $10.7 \%$ were found in both databases, being used in the present analysis. This shows that the journals included in each database are different, and, when no exclusions were used, the number of documents found with both databases were very different. After filtering with the exclusion keywords, the number of documents found was similar in both databases.

It should be highlighted that at the time of the performing of this analysis (September 2019) Scopus already included some documents published in 2020 (34 documents). These documents were not included in the analysis presented below. Moreover, the database did not include the total number of publications for 2019; therefore, this year was not included in the analysis of trends.

\subsubsection{Type of Publication and Language of Publication}

Analyzing the type of publication (Figure 1) shows that most publications are articles/papers (10,633 in WoS and 9479 in Scopus) and conference papers (6372 in WoS and 8768 in Scopus). There is a much lower number of reviews (708 in WoS and 255 in Scopus) and books (133 in WoS and 633 in Scopus). Please note that the sum of publications in all categories is higher than the total number of documents, since both databases catalog some documents as more than one type of publication. 


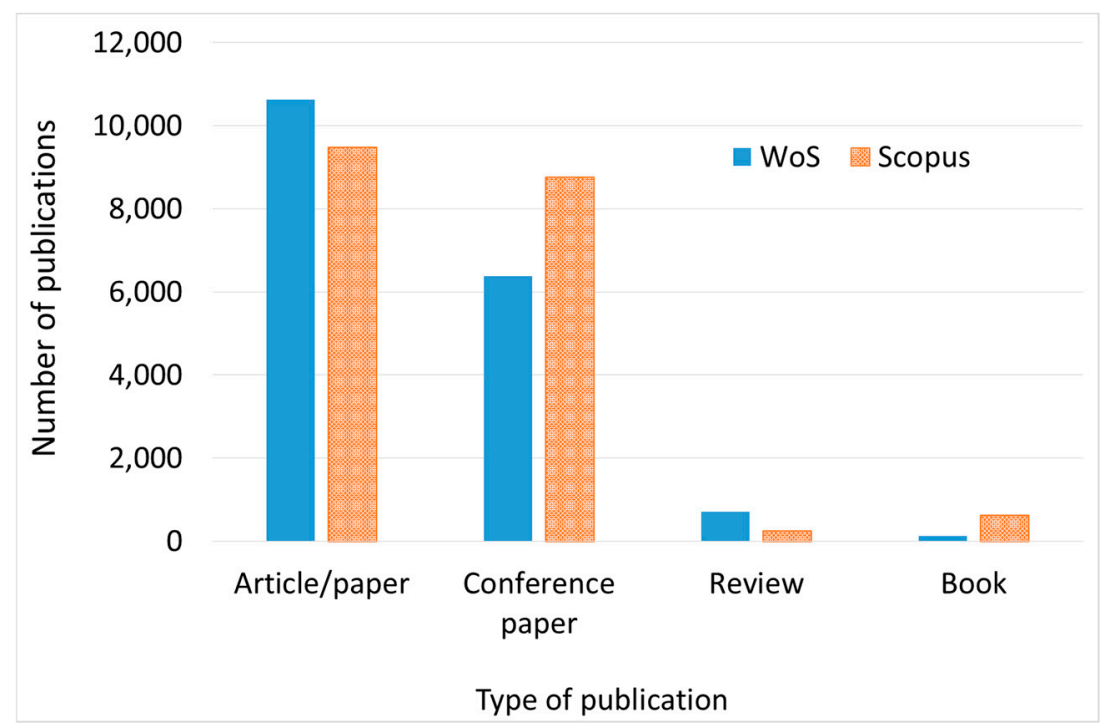

Figure 1. Document type distribution during the period January 2013-September 2019.

Most documents are published in English, namely 98.6\% of the total in WoS and 94.2\% in Scopus (Figure 2). Other prominent languages in WoS are Spanish, German, Portuguese, and Turkish, whereas in Scopus these are Chinese, Japanese, German, and Spanish. The databases differ most on the number of documents in Chinese and Japanese, which are more abundant in Scopus. For example, the country with the most documents on the topic and for the period of study is China. WoS has only 12 documents in Chinese, whereas Scopus has 713, possibly indicating that Scopus includes more journals published in Chinese. Similar are the findings for Japan, a country listed within the 12 with the most documents in both databases, although documents in Japanese can only be found in Scopus (120 documents). Finally, Spanish and German documents are very common and equally found in both databases.

\subsubsection{Trends in Number of Publications}

The trends in the number of publications in the period analyzed (January 2013-September 2019) are presented in Figure 3. In WoS, the number of publications increased in this time period from 1809 to 3462 (doubling the number of documents in this period) and decreased slightly in 2018 to 3028. The average number of publications per year in the period 2013-2018 was 2595. On the other hand, Scopus showed a more constant number of publications per year, with an average of 2922 publications/year in the studied time period.

A comparison of the amount of publications over time in the two databases showed that whereas in 2013 and 2014 there was a difference of nearly 1000 documents among the databases, this difference decreased substantially over time, reaching nearly the same number of documents in 2018.

\subsubsection{Geographic Distribution of the Publications}

Figure 4 shows the amount of publications by country during the time period studied. About the same countries are represented in both databases (Figure $4 a, c:$ WoS, and Figure $4 b$,d: Scopus). All continents are represented in the countries with publications (Figure $4 \mathrm{a}, \mathrm{b}$ ). However, considering only the 25 countries with the most publications (Figure 4c,d), then, in America, only USA, Canada, and Brazil appear; whereas, in Europe, countries from western Europe and Russia appear, and in Asia and Oceania, few countries appear, namely, China, India, and Australia. 


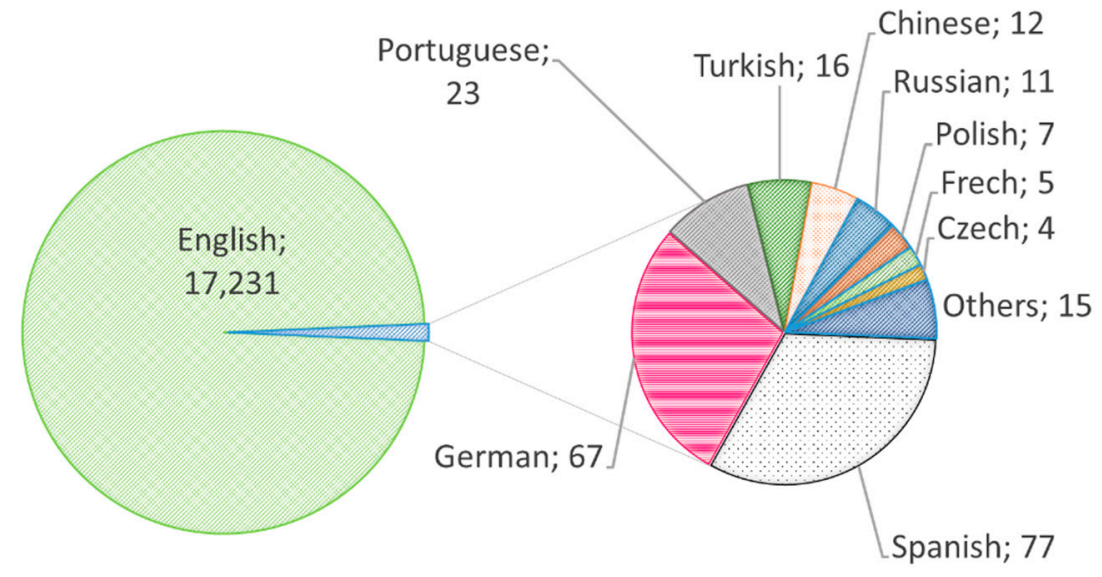

(a)

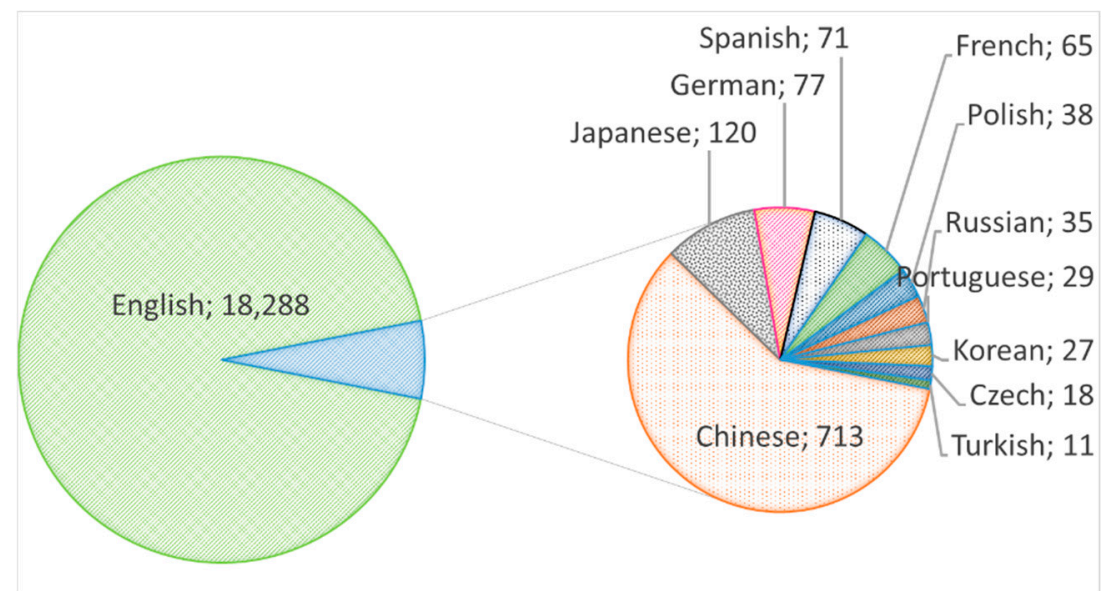

(b)

Figure 2. Distribution by language of documents published during the period January 2013-September 2019: (a) Web of Science; (b) Scopus.

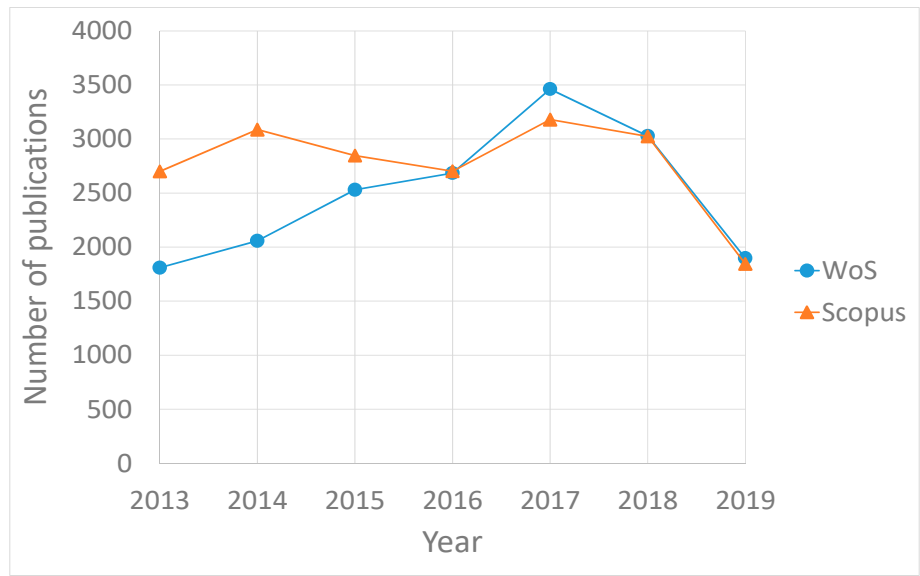

Figure 3. Trends in number of publications in the area of study in the period studied. Blue line: Web of Science, red line: Scopus. 


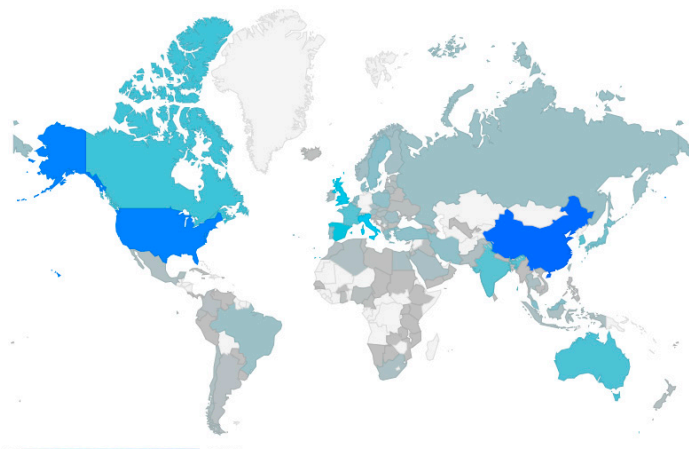

(a)
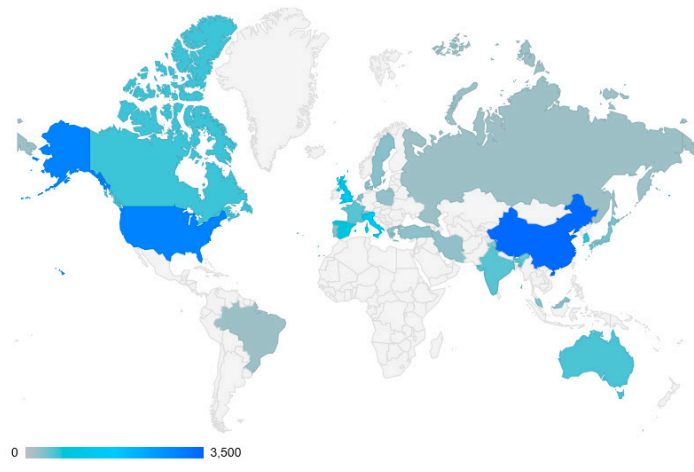

(c)
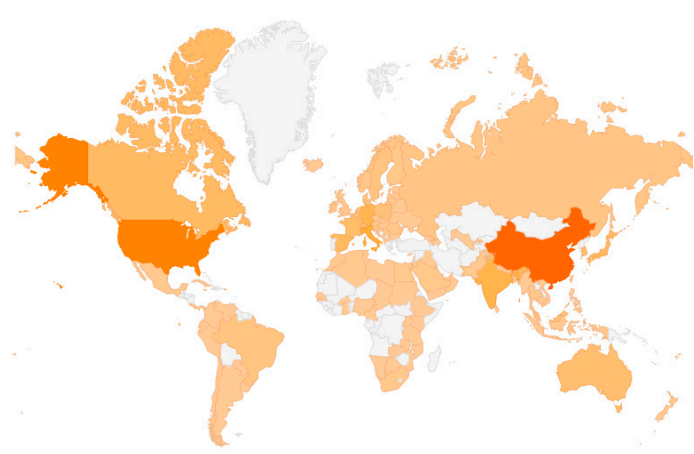

(b)
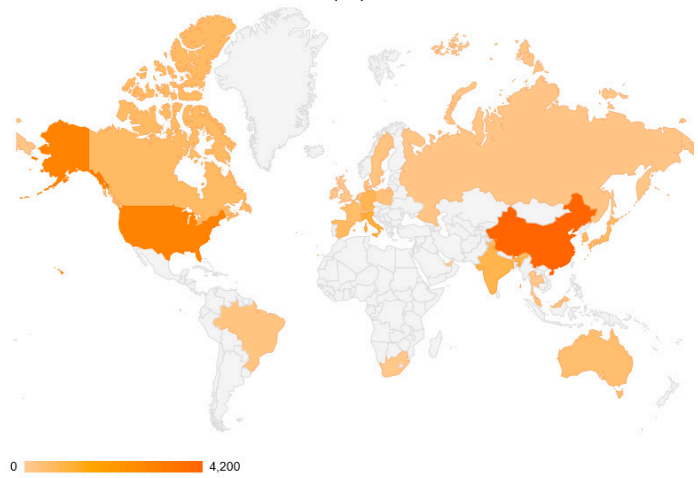

(d)

Figure 4. Geographical distribution of the documents studied: (a) Web of Science; (b) Scopus; (c) 25 countries with the greatest number of publications in Web of Science; and (d) 25 countries with the greatest number of publications in Scopus.

Figure 5 shows the networks obtained with VOSviewer for both databases. The networks show that most clusters given by VOSviewer group the countries by continent; for example, one cluster includes Asia and Oceania with China, Singapore, and Australia, and another cluster includes mainly all European countries (United Kingdom, Germany, Italy, Spain, France, etc.). The countries with the most publications are China and the USA, and they collaborate closely. China shows also close collaboration with Japan, Singapore, and UK in Europe, whereas the USA has more collaboration with South Korea, Canada, and Germany in Europe. Additionally, the network shows strong links between the European countries.

Figure 6 shows the distribution of the total scientific production per country and the number of publications per million inhabitants per country. In both databases, the countries with the most publications and their order are the same, namely China, the USA, Italy, and the UK. The average numbers of publications per year (in the period 2013-2018) were 491 in WoS and 613 in Scopus for China, 449 in WoS and 448 in Scopus for the USA, 205 in WoS and 174 in Scopus for Italy, and 169 in WoS and 166 in Scopus for the UK. Again here, China produced the most publications found in Scopus. Both the databases were in agreement on the nine countries with the most documents: China, the USA, Italy, the UK, Spain, Germany, South Korea, Canada, and India. The remaining country is Australia in WoS and Japan in Scopus. Moreover, the biggest difference in the countries' relative contributions is found for India, which is 10th in WoS and 5th in Scopus. Within these 10 top countries, the European ones have a total of 4024 documents in WoS and 3789 documents in Scopus, a total number of documents in the same range as that in China and USA. 


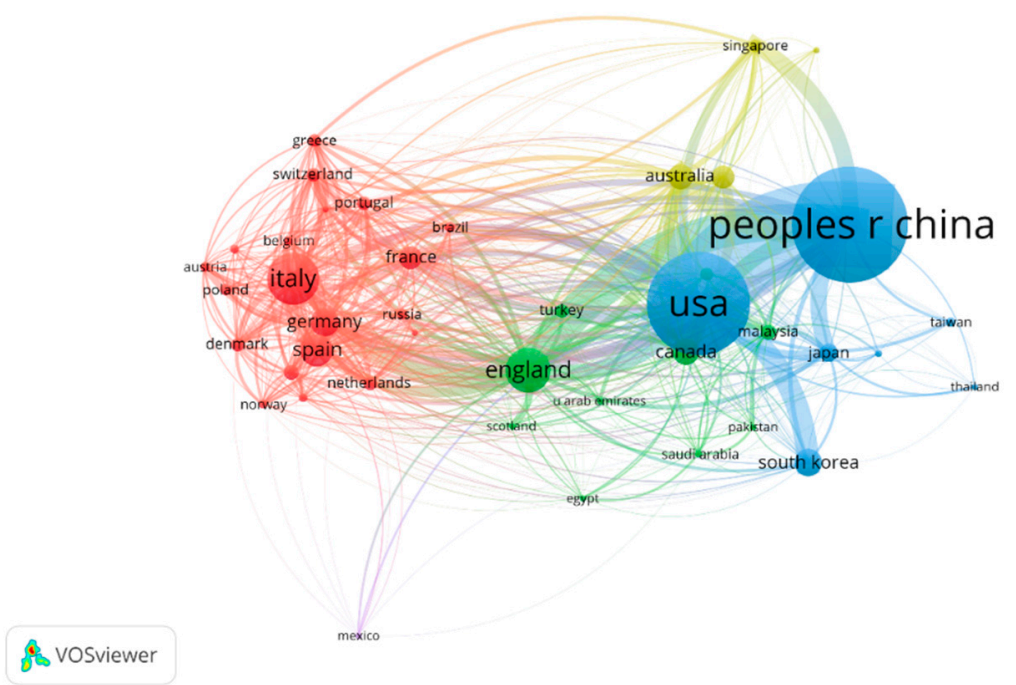

(a)

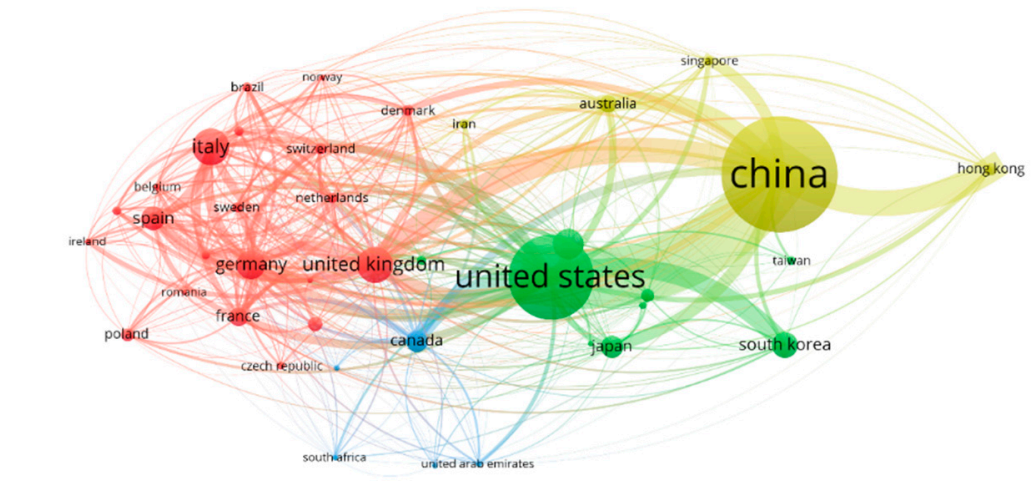

fov vosviewer

(b)

Figure 5. Network of countries with the highest number of documents in the topic of study during the period January 2013-September 2019: (a) Web of Science; (b) Scopus.

China and the USA lead the scientific production with a total of 2721 and 2310 publications, respectively, in the time period studied. Their average is 418 and 355 publications per year, respectively. Next, the European countries Italy, the UK, Spain, and Germany, as well as South Korea appear with $982,931,592,581$, and 540, respectively. The remaining countries have fewer than 500 publications in total. Notably, if the European Union is considered as one entity, the total number of publications in the period of study is 4081 , twice as much as China and the USA.

When comparing the number of publications per capita, the country ranking changes completely. Data of population per country were retrieved from the United Nations [37]. Populous countries like China, India, Brazil, and the USA have a low number of publications per capita (2.41 in WoS and 2.94 in Scopus for China, 0.41 in WoS and 0.69 in Scopus for India, 1.07 in WoS and 1.32 in Scopus for Brazil, and 9.27 in WoS and 9.04 in Scopus for the USA). On the other hand, the countries with the highest number of publications per capita are Denmark (52.56 in WoS and 56.24 in Scopus) and Switzerland (36.34 in WoS and 38.37 in Scopus), which have much smaller populations. Other countries with high numbers of publications per capita are Sweden, Australia, and Italy. Singapore has a very high number of publications per capita in WoS (49.27), but it is not listed in the top 25 countries with the most publications in Scopus. Similarly, Ireland is found in the top 25 countries in Scopus and has a high 
number of publications per capita (28.81), but it is not listed in WoS. In both databases, Spain is found near the average of the countries studied with 17.08 documents per capita in WoS and 14.64 in Scopus.

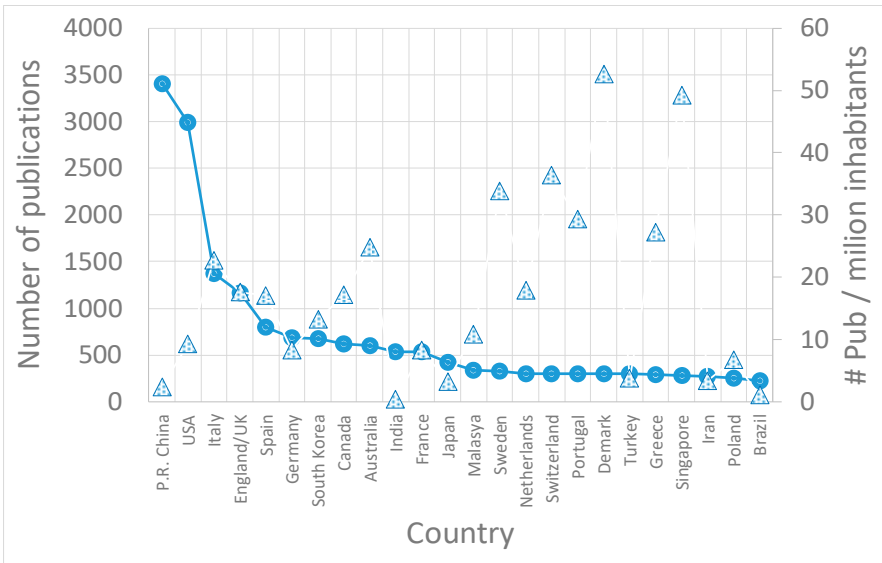

(a)

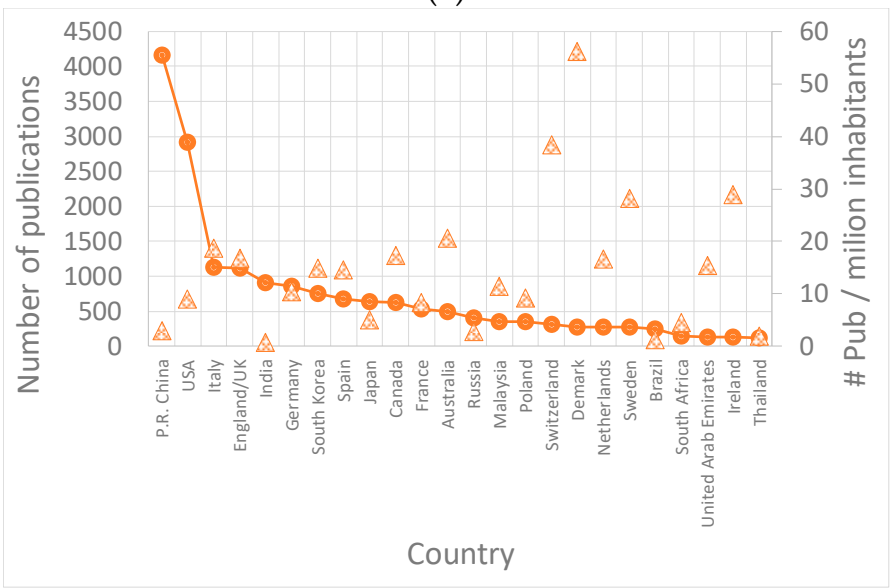

(b)

Figure 6. Scientific production per country (continuous line) during the period January 2013-September 2019 and number of publications per million inhabitants (single marker): (a) Web of Science; (b) Scopus.

The trends in the number of publications for the countries with the most documents are shown in Figure 7. The two databases give different trends for both China and the USA, which are the top producers of publications in this field. Although China in WoS shows a peak in publications in 2017, in Scopus, the trend is more irregular with peaks in 2014 and 2018. The USA shows a slight increase in the number of documents in WoS, which corresponds to a quite pronounced decrease in Scopus. China has the most publications in both databases, reaching over 200 more documents in WoS in 2017. WoS presents the h-index and the average citation per item (ACI) for a given country in a given period (this feature is not provided by Scopus). In the time period of this study, China had an h-index of 56 and an ACI of 7.27, and the USA had an h-index of 62 and an ACI of 9.53, meaning that the publications from the USA are more cited than those from China.

The other countries have similar trends and number of documents in both databases. When looking at the h-index and ACI of these countries, we note that the UK shows a high ACI (10.07), followed by the USA, Italy, Spain, and China (9.53, 8.76, 7.27, and 7.27, respectively). India has a low ACI compared with these countries (5.52). The h-index follows a decreasing trend for the countries analyzed here but not in the same order as the number of publications. The h-index trend is the USA, China, the UK, Italy, Spain, and India (with 62, 56, 46, 44, 34, and 25, respectively). 


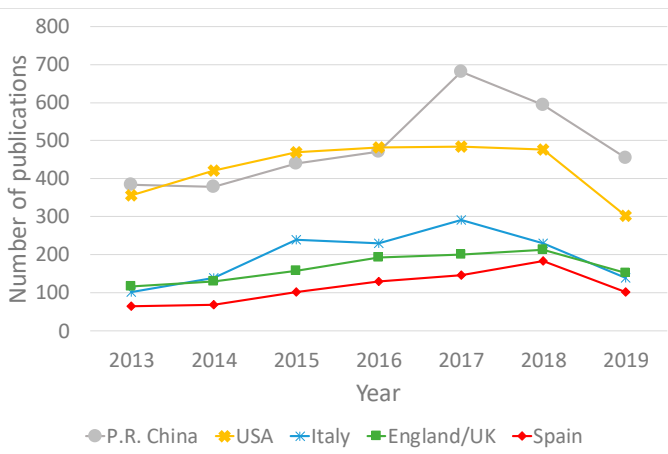

(a)

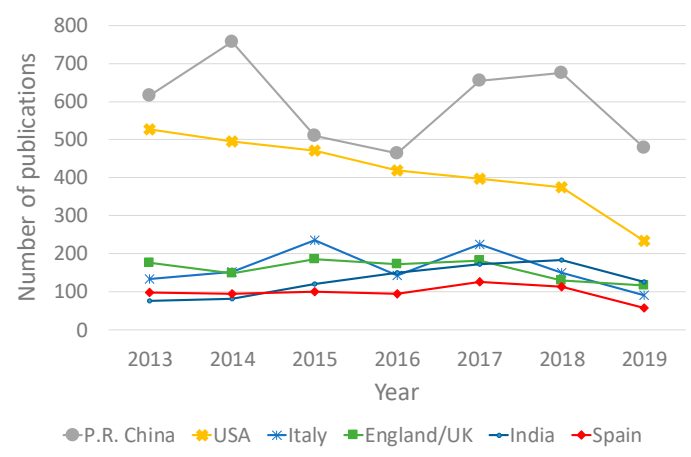

(b)

Figure 7. Trends in the number of publications in the area of study for the five countries with most publications: (a) Web of Science; (b) Scopus. Note that India ranks 10 in Web of Science, while Spain ranks 8 in Scopus.

\subsubsection{Institutional Distribution of the Publications}

The institutional networks are very different for WoS and Scopus (Figure 8); in fact, with Scopus (Figure $8 b$ ), faculties and departments are shown, and, therefore, we do not really know the institutions working on the topic. On the other hand, WoS provides the institutions with the most documents, which are the University of California Berkeley (USA), Tsinghua University (China), Hong Kong Polytechnical University (China), and the Polytechnic University of Torino (Italy). Strong links are seen between the University of California Berkeley and Tsinghua University (confirming the strong links found between both countries before). The network also shows strong links between institutes with low number of documents, such as Aalto University (Finland) and Tallinn University of Technology (Estonia), University of Maryland and Shandong Jianzhu University, or University of Perugia (Italy) and University of Lleida (Spain).

The institutes with the highest number of publications in the topic of study in the period 2013-September 2019 are shown in Figure 9. The results are quite different for the two databases used. In WoS in the first and second places, there are two US institutes: the US Department of Energy with a total of 458 publications, an average of 67 publications/year, an h-index of 39, and an ACI of 13.03; and the University of California system with a total of 292 publications, an average of 45 publications/year, an h-index of 38, and an ACI of 17.24. Moreover, the Lawrence Berkeley National Laboratory appears in 5th place, with a total of 209 publications, an average of 30 publications/year, an h-index of 34, and an ACI of 18.17. Although as a country, China is the first one, its institutes come later, but five of them are within the ten first institutes. Tsinghua University is the third institute (with a total of 263 publications, an average of 38 publications/year, an h-index of 29, and an ACI of 12.64), the Polytechnic University of Hong Kong is the sixth (with a total of 169 publications, an average of 24 publications/year, an h-index of 24, and an ACI of 12.15), the Chinese Academy of Sciences is the seventh (with a total of 179 publications, an average of 25 publications/year, an h-index of 22, and an ACI of 10.01), Tongji University is the eighth (with a total of 179 publications, an average of 26 publications/year, an h-index of 19, and an ACI of 6.91), and Tianjin University is the tenth (with a total of 159 publications, an average of 23 publications/year, an h-index of 20, and an ACI of 8.01). Moreover, the US institutes had a greater impact than those of China.

Between these American and Chinese institutes, only another two institutes appear: CNRS from France (with a total of 213 publications, an average of 31 publications/year, an h-index of 18, and an ACI of 7.60) and the Polytechnic University of Turin in Italy (with a total of 165 publications, an average of 26 publications/year, an h-index of 20, and an ACI of 10.16). The Polytechnic University of Turin has fewer publications than CNRS but with higher impact. 


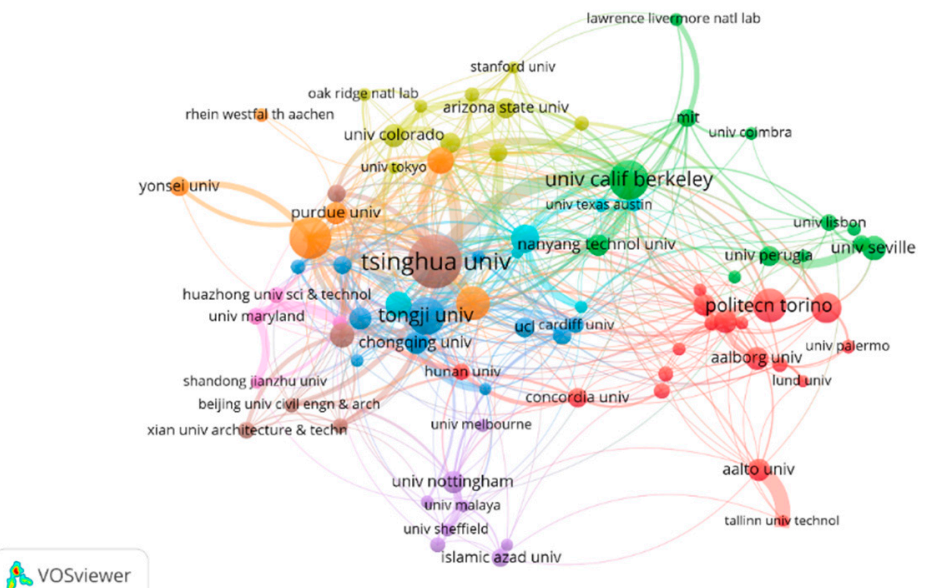

(a)

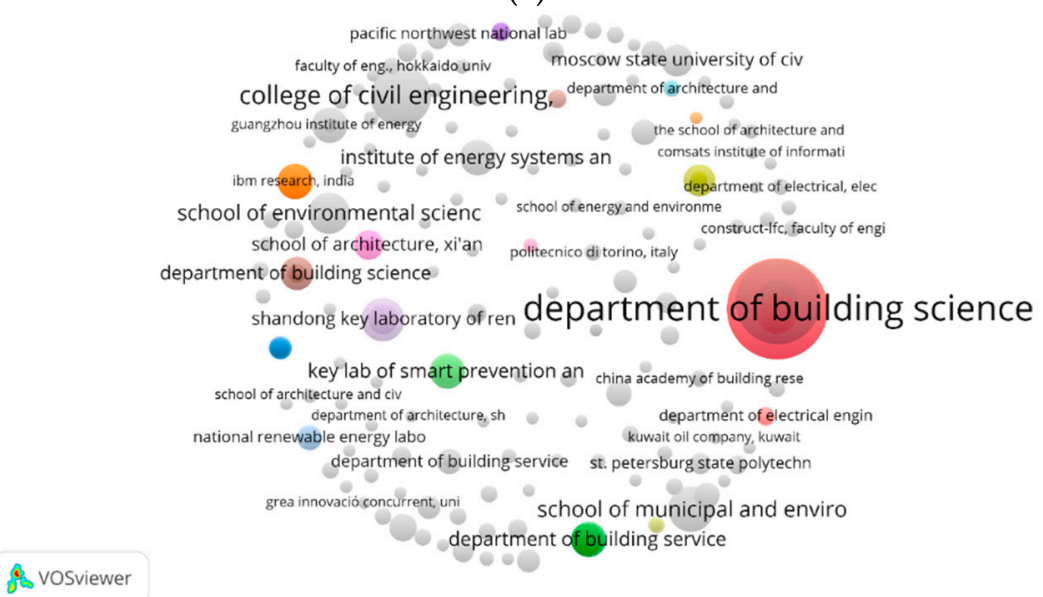

(b)

Figure 8. Institutional networks with the highest number of documents in the topic of study during the period January 2013-September 2019: (a) Web of Science; (b) Scopus.

In Scopus (Figure 9b), 8 out of the 10 top institutes are in China (Ministry of Education of China with 349 documents, Tsinghua University with 331, Hong Kong Polytechnic University with 171, Tongji University with 161, Tianjin University with 156, Southeast University with 154, Harbin Institute of Technology with 149, and Chinese Academy of Science with 117). The other institutes listed within the top 10 are the Polytechnic University of Turin (4th with 166 documents) and the Polytechnic University of Milan (9th with 118 documents), both in Italy.

It should be highlighted that Scopus does not list any USA institute within the top 10 list; the Georgia Institute of Technology is in the 21st position, whereas the US Department of Energy is not listed at all.

\subsubsection{Analysis of Authors}

Figure 10 shows the author networks using both databases, which are very different. WoS author coverage is worldwide, whereas in Scopus, the network is dominated by Chinese authors. It is not easy to identify the authors with more publications because sometimes publication lists for different authors with the same name and surname are aggregated. The figure should therefore be interpreted with caution because several authors, for example with name Y. Wang, appear merged and can distort the analysis. 


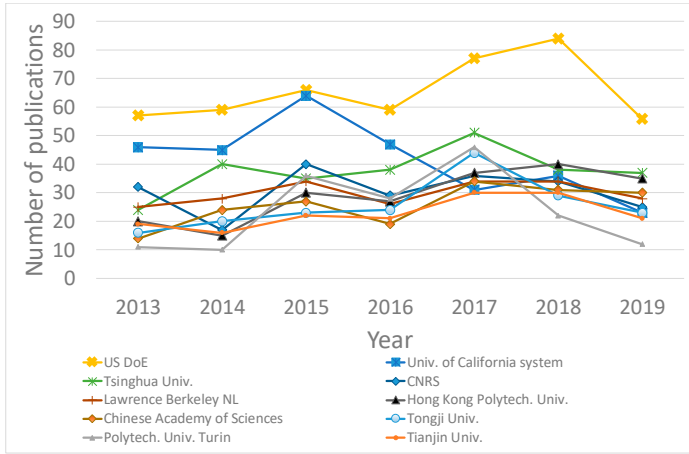

(a)

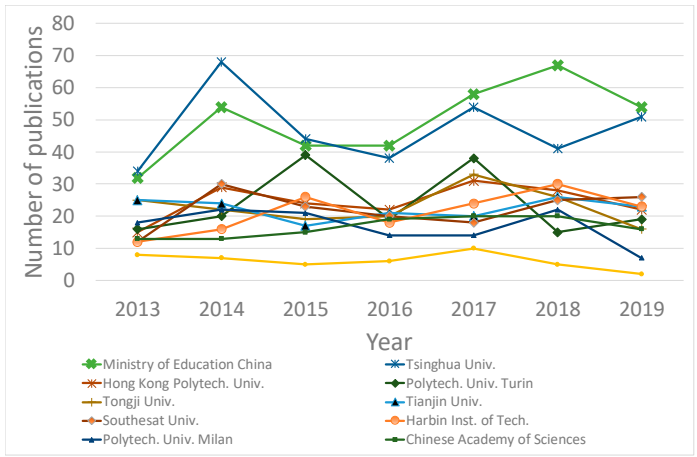

(b)

Figure 9. Trends in the number of publications in the area of study per institution: (a) Web of Science; (b) Scopus.

Table 1 shows the identified authors with the most publications. Those were extracted from the list of WoS and its network (as Scopus does not have a similar feature), and then Scopus was used to find their total number of publications and h-indexes (as WoS does not have a similar feature). The author with the most publications on the topic is Luisa F. Cabeza from the University of Lleida in Spain. She has an h-index of 58, and together with Mattheos Santamouris from the University of New South Wales (h-index $=68$ ) and Shengwei Wang from Hong Kong Polytechnic University (h-index = 52), they are the most senior researchers in the list. On the other hand, there are much more junior researchers such as Jimin Kim from Yonsei University (h-index $=13$ ) and Anna Laura Pisello from University of Perugia (h-index $=27$ ) also included in this list.

The authors with the 10 most publications are from different countries; there are two authors from South Korea, USA, China, and Italy and one author each from Spain and Australia. Regarding the collaborations between these authors (Figure 10, some of the relationships here described are not visible in Figure 10 due to the overlap of forms and names in the visualization), Luisa F. Cabeza is strongly related with Anna Laura Pisello, who shows association with John E. Taylor (Virginia Tech, USA) and Mattheos Santamouris. The latter, on the other hand, is related to Fabrizio Ascione (University of Naples Federico II, Italy), Giuseppe Peter Vanoli (University of Molise, Italy), and Burcin Becerik-Geber (University of Southern California, USA). Another group of related authors is that of Tianzhen Hong, Da Yan, Stefano P. Corgnati, and William O'Brien (Carleton University, Canada). Finally, Shengwei Wang shows a small association with other Chinese authors.

\subsection{Research Trends and Gaps}

\subsubsection{Distribution of Publications by Subject Categories and Journals}

The outputs generated from both databases were organized by subject area (Figure 11). In WoS, the highest percentage refers to the subject of Energy Fuels (40\%), followed by Construction Building Technology (31\%) and Engineering Civil (20\%). All other areas correspond to less than 20\% of the total publications. Even though there are many areas of engineering and construction, computer science, thermodynamics, chemistry, and materials, automation and social sciences are also represented.

Scopus (Figure 11b) has much fewer but broader categories. The first one is Engineering (59\% documents), followed by Energy (27\%) and Computer Science (22\%). As in WoS, all other areas correspond to less than $20 \%$ of the publications. 


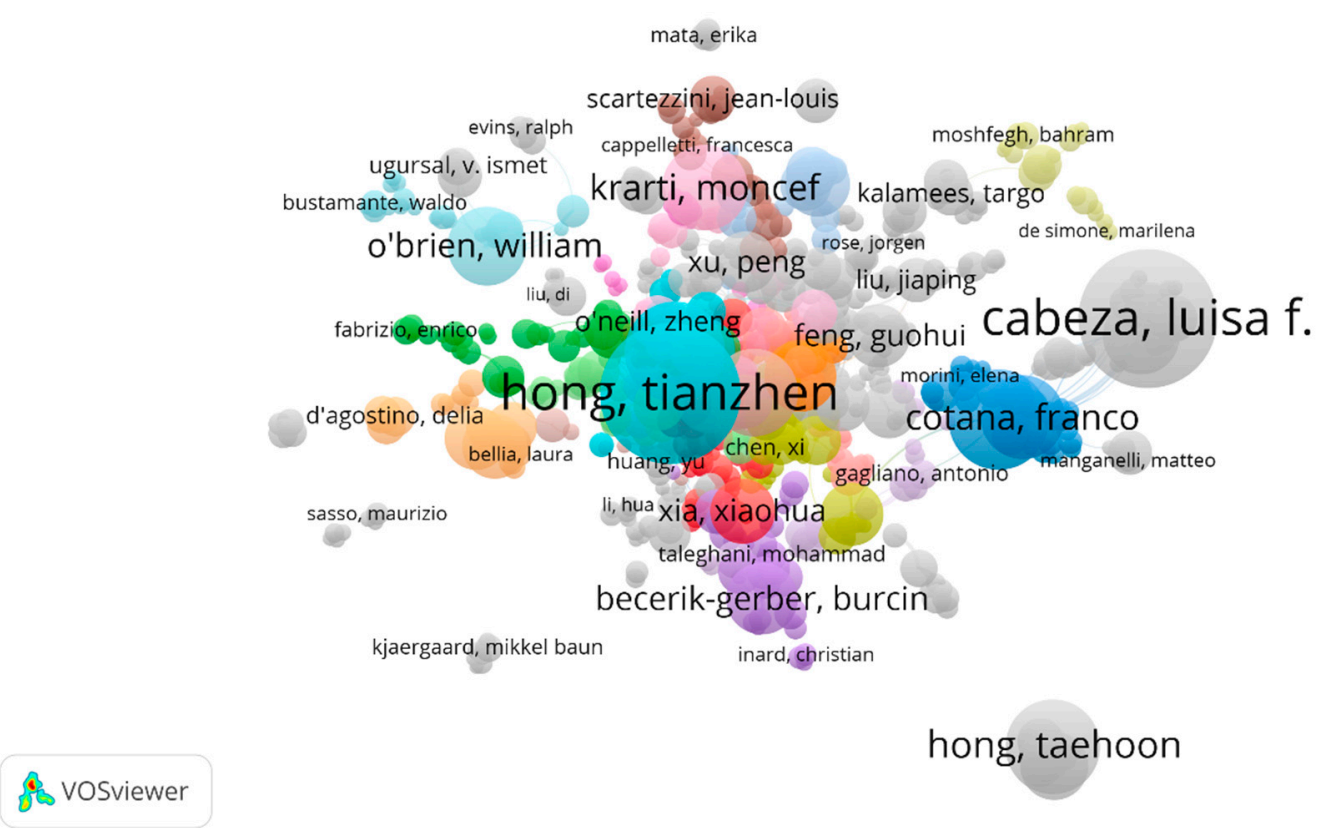

(a)

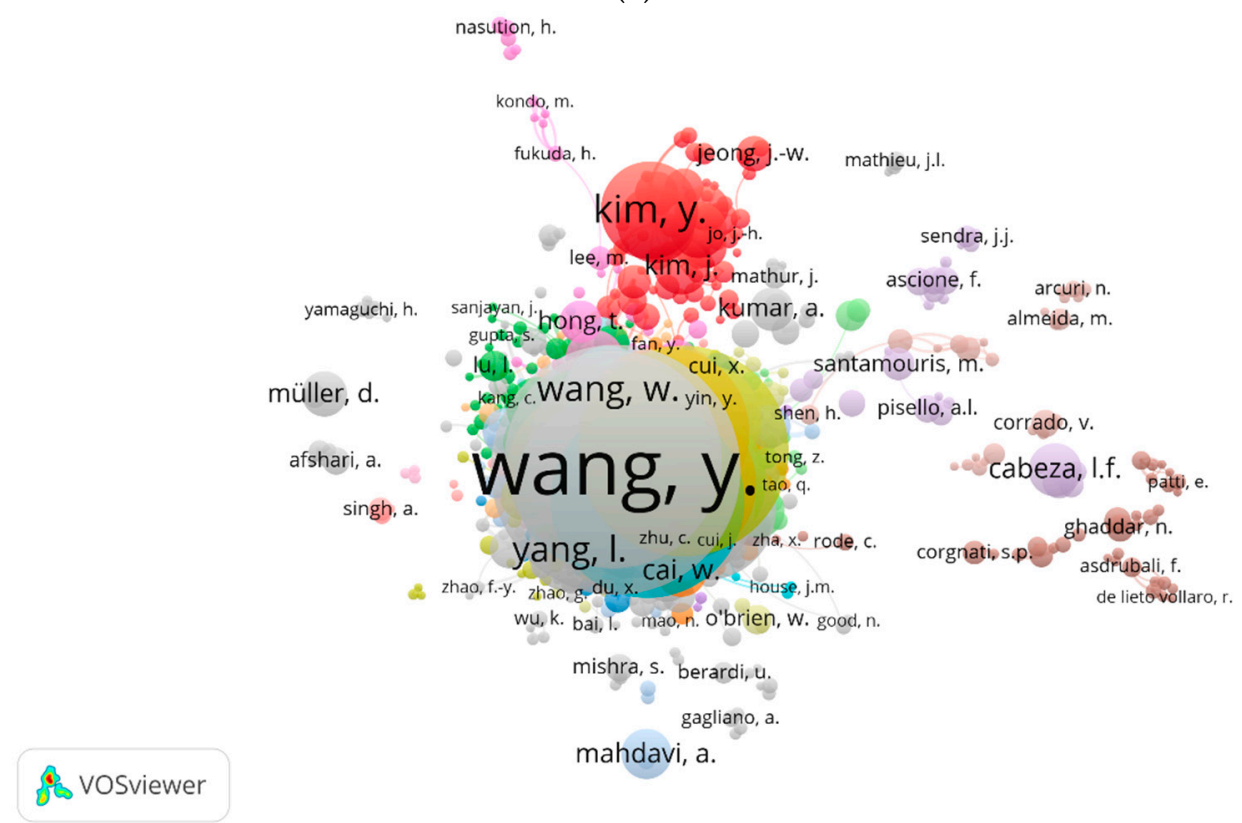

(b)

Figure 10. Co-authorship network: (a) Web of Science; (b) Scopus.

Figure 12 shows the top 15 journals with the most publications in the field of study in the period January 2013-September 2019 for both databases. The most popular journal by far is "Energy and Buildings" in both databases. Moreover, most of the journals fall within the field of energy and engineering. When analyzing the journals in detail (Table 2), the journals devoted to conference proceedings (i.e., Applied Mechanics and Materials, Energy Procedia, IOP Conference Series, and Procedia Engineering) are the ones with the lower impact or even without impact factor, hosting authors with h-indexes between 12 and 21. On the other hand, most journals belong in the first quartile (Q1), with only two belonging to the second quartile (Q2), in the field of Energy and Sustainability. These two journals are fully open access. The journals with the highest impact are Renewable and Sustainable Energy Reviews and Energy Policy, with h-indexes of 147 and 80, respectively. The most 
popular journal is third in impact, Energy and Buildings, with an h-index of 70 in the period of study (2013-September 2019).

Table 1. Authors with the highest number of publications in the field of study between January 2013 and September 2019. WoS is Web of Science.

\begin{tabular}{|c|c|c|c|c|c|c|}
\hline Author & Institution & Country & $\begin{array}{c}\text { No. of } \\
\text { Publications on } \\
\text { the Topic During } \\
\text { the Period in } \\
\text { WoS }\end{array}$ & $\begin{array}{l}\text { Total No. of } \\
\text { Documents } \\
\text { in Scopus }\end{array}$ & $\begin{array}{l}\text { Total No. of } \\
\text { Citations in } \\
\text { Scopus }\end{array}$ & $\begin{array}{c}\text { Total } \\
\text { h-Index in } \\
\text { Scopus }\end{array}$ \\
\hline Luisa F. Cabeza & University of Lleida & Spain & 62 & 410 & 16,467 & 58 \\
\hline Jimin Kim & Yonsei University & South Korea & 61 & 53 & 651 & 13 \\
\hline Tianzhen Hong & $\begin{array}{l}\text { Laurence Berkeley } \\
\text { National Laboratory }\end{array}$ & USA & 60 & 110 & 2286 & 31 \\
\hline $\begin{array}{c}\text { Mattheos } \\
\text { Santamouris }\end{array}$ & $\begin{array}{c}\text { University of New } \\
\text { South Wales }\end{array}$ & Australia & 55 & 394 & 15,002 & 68 \\
\hline $\begin{array}{l}\text { Anna Laura } \\
\text { Pisello }\end{array}$ & University of Perugia & Italy & 50 & 134 & 2053 & 27 \\
\hline Da Yan & Tsinghua University & China & 43 & 86 & 1680 & 21 \\
\hline Taehoon Hong & Yonsei University & South Korea & 42 & 175 & 2742 & 30 \\
\hline Shengwei Wang & $\begin{array}{l}\text { Hong Kong } \\
\text { Polytechnic } \\
\text { University }\end{array}$ & China & 38 & 300 & 7945 & 52 \\
\hline $\begin{array}{l}\text { Stefano P. } \\
\text { Corgnati }\end{array}$ & $\begin{array}{c}\text { Polytechnic } \\
\text { University of Turin }\end{array}$ & Italy & 35 & 112 & 2557 & 28 \\
\hline Moncef Krarti & $\begin{array}{l}\text { University of } \\
\text { Colorado Boulder }\end{array}$ & USA & 35 & 175 & 2571 & 28 \\
\hline
\end{tabular}

\subsubsection{Analysis of Keywords}

The keywords found in the search in Scopus are presented in Table 3 grouped by selected topic. Here, they are listed by number of publications, and ranked in the table in descending order of occurrence; therefore, there are, for example, many more publications related to air conditioning ( $n=1887)$ than to heating $(n=1212)$. There is a clear focus on energy issues; thousands of publications use keywords such as energy utilization, energy efficiency, or energy conservation ( $n=5046$ to $n=3541)$, whereas energy management, energy consumption, energy use, and thermal performance are the focus in a substantially lower number of publications $(n=763$ to $n=363)$. Policies and resources appear last.

A second group of keywords relates to building typologies and subsectors, showing that the literature has a higher focus on residential buildings (housing, $n=1215$; residential building, $n=704$; houses, $n=267$ ) than on non-residential premises (office building, $n=1296$; commercial building, $n=319$ ). Then, the occurrence of the keywords "architectural design," "retrofitting," and "historic preservation" seems to indicate a balanced distribution of the literature among interventions on new and existing buildings. 


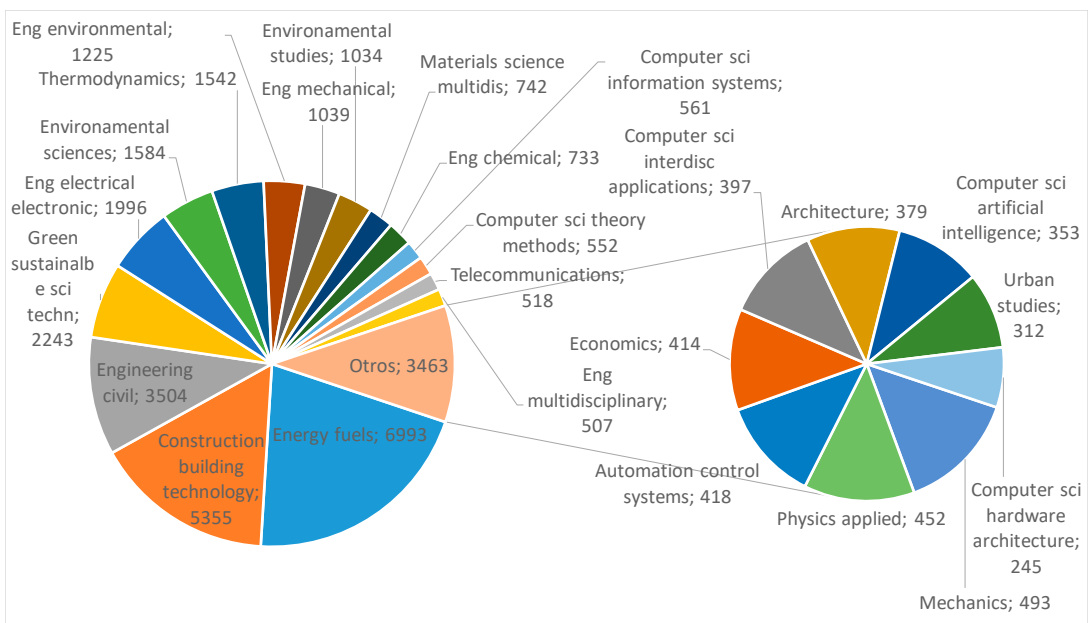

(a)

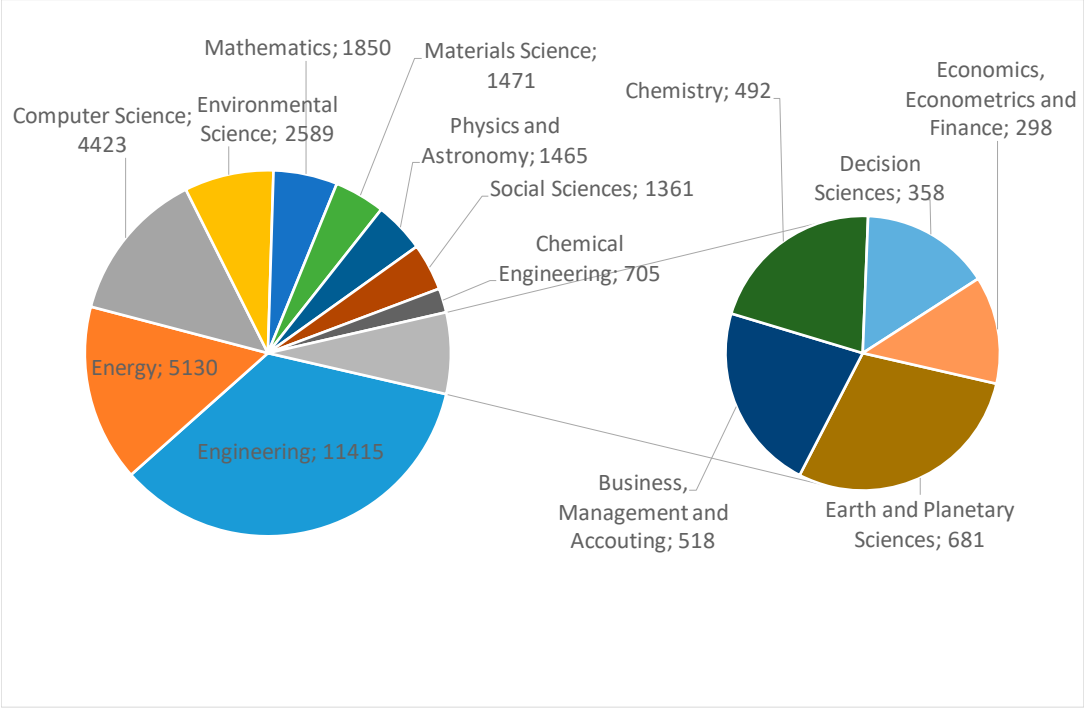

(b)

Figure 11. Distribution per subject area during the period January 2013-September 2019: (a) Web of Science; (b) Scopus.

Technologies are the focus of another group of keywords, with heating, ventilation, and air conditioning (HVAC) attracting the most interest from researchers ("air conditioning", "heating", and "cooling"). Renewable energy ("solar building", $n=270$ ) is a focus; although other renewable energy sources, such as geothermal or biomass, do not appear in this list. A significant number of keywords are related to information and communication technologies (ICT). The most common keywords include generic concepts such as "intelligent buildings", or "internet of things", as well as solutions ("climate control", "energy management") and methods ("optimization", "algorithms", "simulation", and "computer software"). This technological literature niche is well populated, so we performed a more in-depth review of the publications included therein [38].

A final set of keywords is related to sustainability ("sustainable development," "life cycle," "environmental impact," and "greenhouse gases"), costs and economy (costs and cost benefit analysis), and comfort ("thermal comfort", $n=669$; "heat transfer", $n=648$; "temperature", $n=386$ ). 


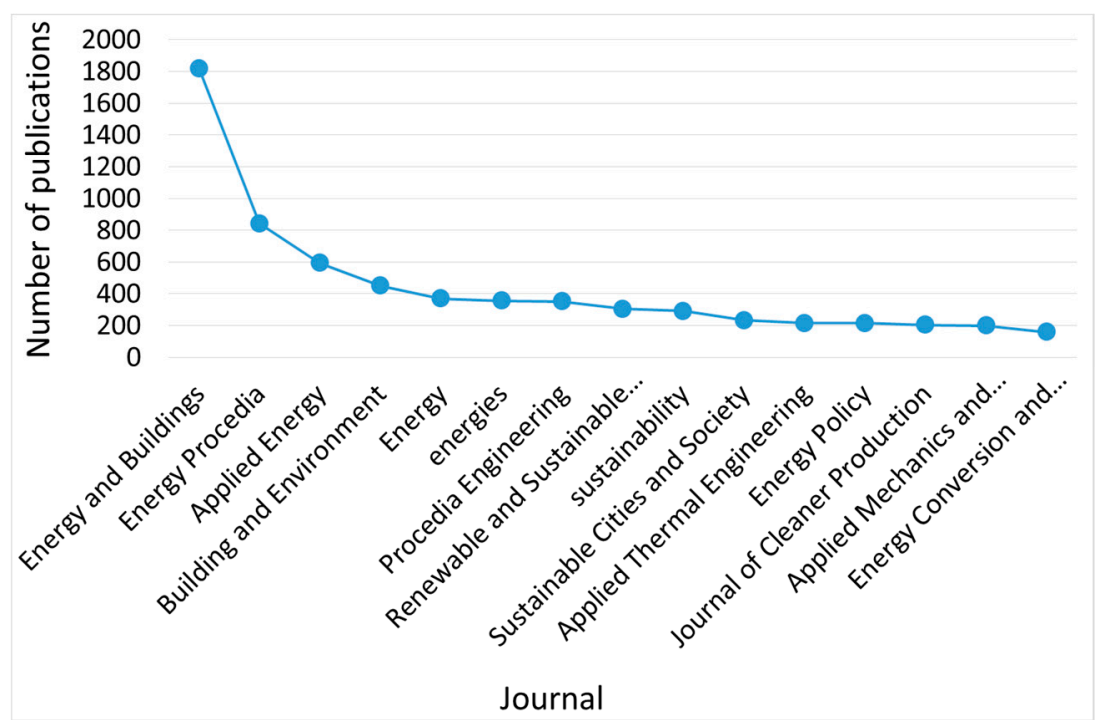

(a)

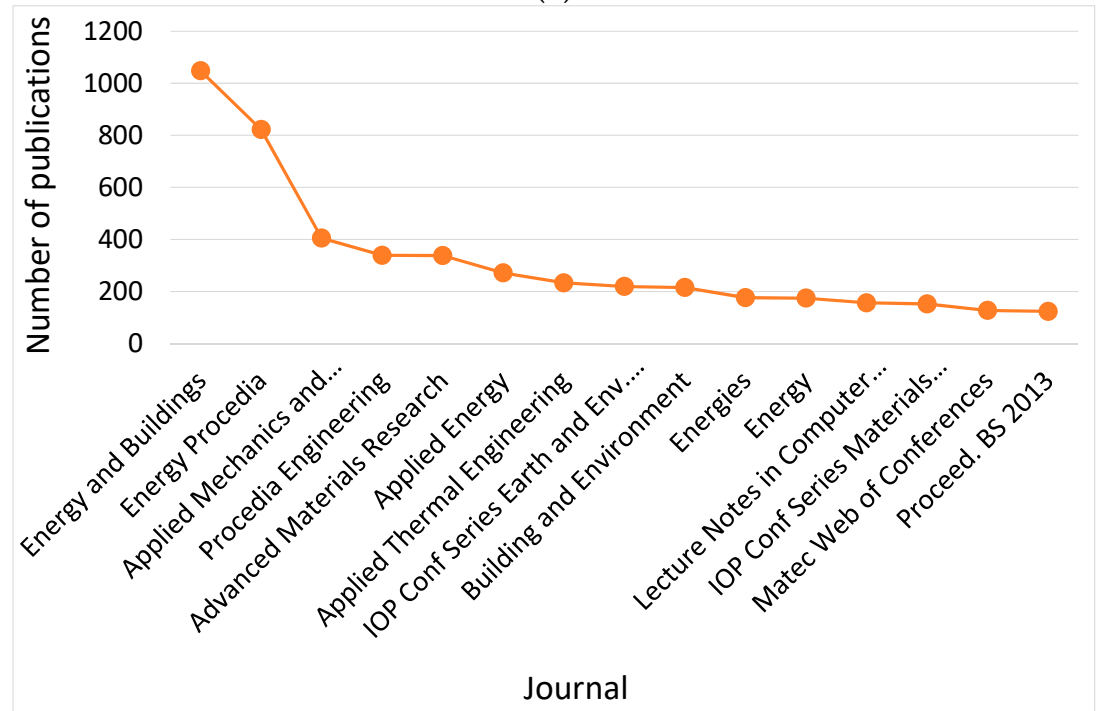

(b)

Figure 12. Number of publications in the top 15 journals used in the area of study: (a) Web of Science; (b) Scopus.

Figure 13 shows a word cloud with the most frequently occurring words in the abstracts and titles of the documents for both databases. Each point in the item density visualization has a color that indicates the density of items at that point. The larger the number of items near a point and the higher the weights of the neighboring items, the closer the color of the point is to yellow. The other way around, the smaller the number of items about a point and the lower the weights of the neighboring items, the closer the color of the point is to blue. 
Table 2. Journals where most articles have been published during the period of study, and their impact.

\begin{tabular}{|c|c|c|c|c|c|}
\hline Journal & $\begin{array}{l}\text { No. of Publications } \\
\text { in WoS }\end{array}$ & $\begin{array}{l}\text { No. of Publications } \\
\text { in Scopus }\end{array}$ & Category $^{1}$ & h-Index ${ }^{2}$ & $\begin{array}{l}\text { Full Open } \\
\text { Access }\end{array}$ \\
\hline Advanced Materials Research & - & 338 & - & 15 & No \\
\hline Applied Energy & 594 & 271 & Q1 & 53 & No \\
\hline Applied Mechanics and Materials & 200 & 405 & - & 12 & No \\
\hline Applied Thermal Engineering & 316 & 233 & Q1 & 65 & No \\
\hline Building and Environment & 451 & 215 & Q1 & 63 & No \\
\hline Energies & 356 & 176 & Q2 & 31 & Yes \\
\hline Energy & 369 & 174 & Q1 & 58 & No \\
\hline Energy and Buildings & 1820 & 1048 & Q1 & 70 & No \\
\hline Energy Conversion and Management & 158 & - & Q1 & 29 & No \\
\hline Energy Policy & 214 & - & Q1 & 80 & No \\
\hline Energy Procedia & 842 & 822 & - & 21 & Yes \\
\hline $\begin{array}{l}\text { IOP Conference Series: Materials } \\
\text { Science and Engineering }\end{array}$ & - & 152 & - & - & Yes \\
\hline $\begin{array}{l}\text { IOP Conference Series: Earth and } \\
\text { Environment Science }\end{array}$ & - & 219 & - & - & Yes \\
\hline Journal of Cleaner Production & 204 & - & Q1 & 53 & No \\
\hline Lecture Notes in Computer Science & - & 156 & - & - & No \\
\hline MATEC web of Conferences & - & 127 & - & - & Yes \\
\hline Procedia Engineering & 352 & 339 & - & 20 & Yes \\
\hline Proceedings BS2013 & - & 123 & - & - & Yes \\
\hline $\begin{array}{l}\text { Renewable and Sustainable Energy } \\
\text { Reviews }\end{array}$ & 305 & - & Q1 & 147 & No \\
\hline Sustainability & 291 & - & Q2 & 17 & Yes \\
\hline Sustainable Cities and Society & 233 & - & Q1 & 34 & No \\
\hline
\end{tabular}

${ }^{1} \mathrm{Q}-$ Quartile. Journals in the $25 \%$ top journals of a category are Q1 ${ }^{2}$ In the period of study for the topic considered in WoS.

Table 3. Keywords found in the publications (in brackets the number of occurrences) according to Scopus database. The keywords are ranked in descending order of occurrence.

\begin{tabular}{|c|c|c|c|c|}
\hline Related to Energy & Related to Building & $\begin{array}{l}\text { Related to Technologies } \\
\text { or Systems }\end{array}$ & $\begin{array}{l}\text { Related to ICT and } \\
\text { Control }\end{array}$ & Other \\
\hline Energy utilization (5046) & Buildings (2439) & Air conditioning (1887) & $\begin{array}{l}\text { Intelligent buildings } \\
(941)\end{array}$ & $\begin{array}{c}\text { Sustainable } \\
\text { development (916) }\end{array}$ \\
\hline $\begin{array}{l}\text { Energy efficiency } \\
(4232)\end{array}$ & $\begin{array}{l}\text { Office buildings } \\
\text { (1296) }\end{array}$ & Heating (1212) & Optimization (877) & Costs $(800)$ \\
\hline $\begin{array}{c}\text { Energy conservation } \\
(3541)\end{array}$ & $\begin{array}{c}\text { Housing } \\
(1215)\end{array}$ & $\begin{array}{c}\text { Cooling } \\
(855)\end{array}$ & $\begin{array}{l}\text { Algorithms } \\
\text { (387) }\end{array}$ & $\begin{array}{l}\text { Thermal comfort } \\
(669)\end{array}$ \\
\hline $\begin{array}{c}\text { Energy management } \\
(763)\end{array}$ & $\begin{array}{c}\text { Architectural design } \\
(835)\end{array}$ & $\begin{array}{l}\text { Ventilation } \\
\quad(741)\end{array}$ & $\begin{array}{l}\text { Energy management } \\
\text { systems (370) }\end{array}$ & $\begin{array}{l}\text { Heat transfer } \\
(648)\end{array}$ \\
\hline $\begin{array}{l}\text { Energy consumption } \\
(644)\end{array}$ & $\begin{array}{l}\text { Residential building } \\
\text { (704) }\end{array}$ & $\begin{array}{l}\text { Heat pump systems } \\
(383)\end{array}$ & $\begin{array}{c}\text { Climate control } \\
(358)\end{array}$ & $\begin{array}{c}\text { Temperature } \\
(386)\end{array}$ \\
\hline $\begin{array}{c}\text { Energy use } \\
(411)\end{array}$ & $\begin{array}{c}\text { Retrofitting } \\
(376)\end{array}$ & $\begin{array}{l}\text { Phase change materials } \\
\text { (367) }\end{array}$ & $\begin{array}{c}\text { Computer software } \\
\text { (352) }\end{array}$ & $\begin{array}{c}\text { Greenhouse gases } \\
(370)\end{array}$ \\
\hline $\begin{array}{l}\text { Thermal performance } \\
\text { (395) }\end{array}$ & $\begin{array}{l}\text { Commercial building } \\
\text { (319) }\end{array}$ & $\begin{array}{c}\text { Domestic appliances } \\
(344)\end{array}$ & $\begin{array}{l}\text { Forecasting } \\
\quad(362)\end{array}$ & $\begin{array}{l}\text { Life cycle } \\
\quad(360)\end{array}$ \\
\hline $\begin{array}{l}\text { Building energy } \\
\text { consumption } \\
(383)\end{array}$ & $\begin{array}{l}\text { Historic preservation } \\
\text { (268) }\end{array}$ & $\begin{array}{l}\text { Pumps } \\
\text { (335) }\end{array}$ & $\begin{array}{l}\text { Internet of things } \\
\qquad(282)\end{array}$ & $\begin{array}{l}\text { Simulation } \\
\text { (323) }\end{array}$ \\
\hline $\begin{array}{l}\text { Energy policy } \\
\text { (373) }\end{array}$ & $\begin{array}{c}\text { Houses } \\
(267)\end{array}$ & $\begin{array}{l}\text { Solar building } \\
\text { (270) }\end{array}$ & $\begin{array}{l}\text { Cloud computing } \\
\text { (257) }\end{array}$ & $\begin{array}{l}\text { Cost benefit } \\
\text { analysis } \\
(274)\end{array}$ \\
\hline $\begin{array}{c}\text { Energy resources } \\
(244)\end{array}$ & - & $\begin{array}{c}\text { Renewable energies } \\
\text { (261) }\end{array}$ & - & $\begin{array}{c}\text { Emission control } \\
(260)\end{array}$ \\
\hline
\end{tabular}




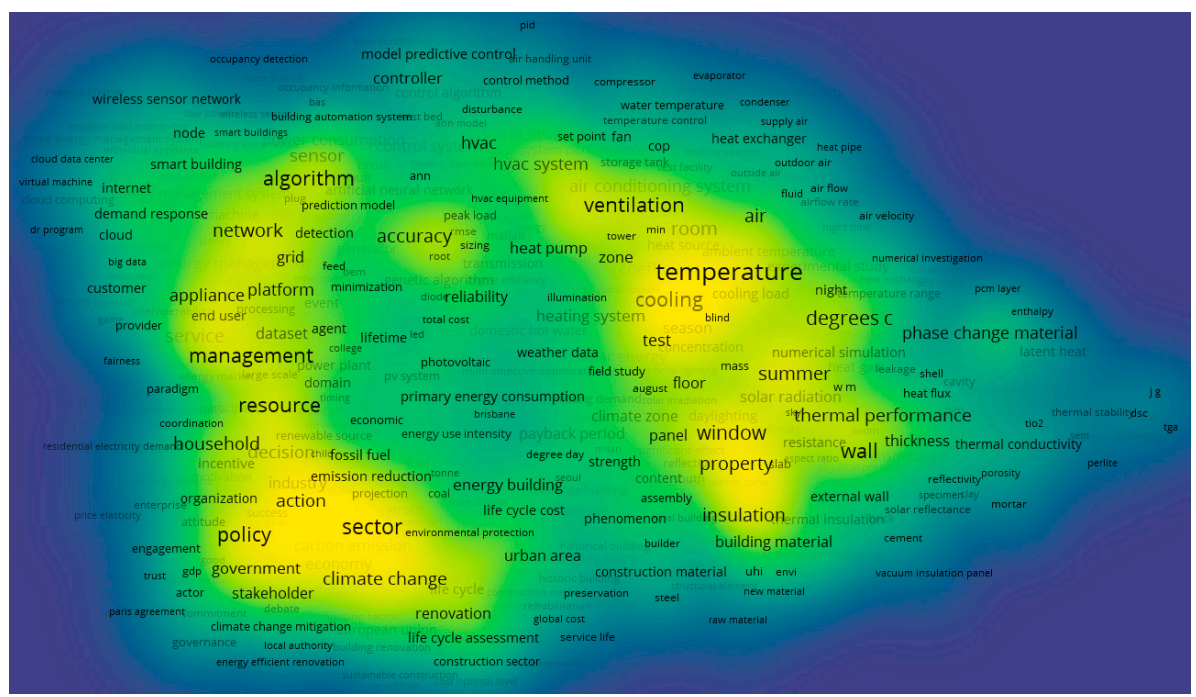

(a)

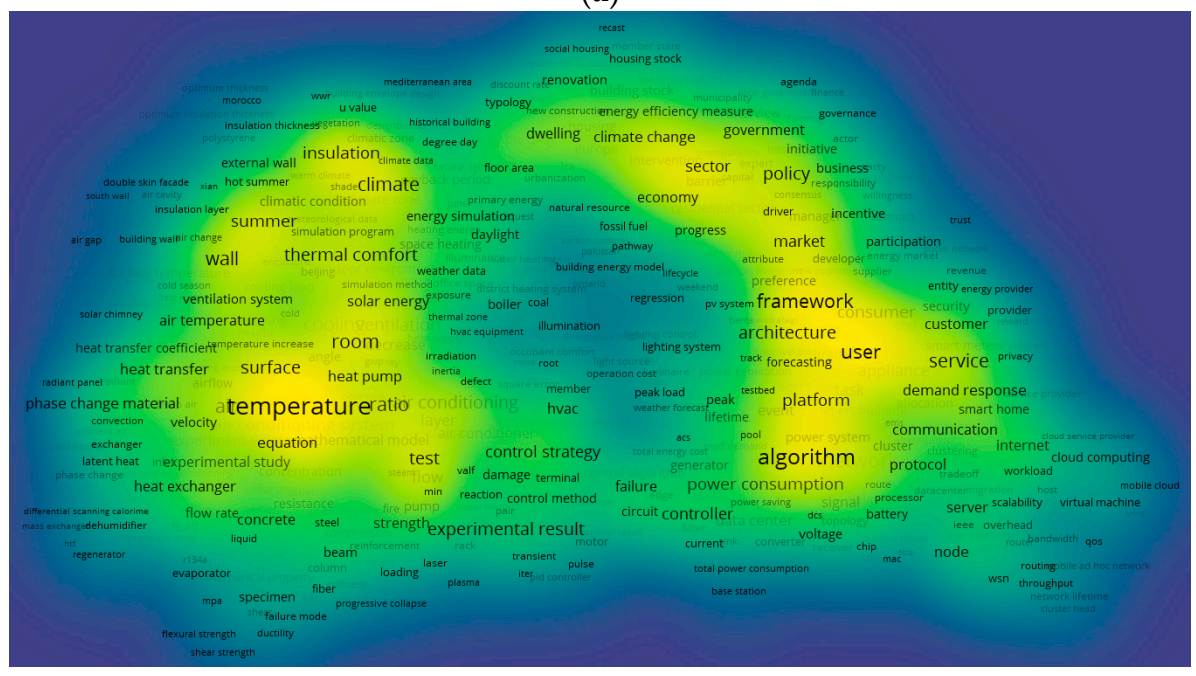

(b)

Figure 13. Density visualization of word occurrence at title and abstract level in (a) Web of Science and (b) Scopus.

\subsubsection{Co-Occurrence}

Figure 14 shows details of the co-occurrence map, where the red cluster includes terms such as "climate change," "building sector," "policy," and "resource"; in this cluster, there is no relation with technologies. In the second cluster, (green) terms such as "temperature," "cooling," "thermal comfort," and "ventilation" appear, indicating a relationship between cooling and technologies (Figure 14a), and ventilation and technologies (Figure 14b). On the other hand, "heating" is not a keyword in this co-occurrence map. The blue cluster groups more terms with technologies, not only hard technologies such as "HVAC" or "HVAC system" (Figure 14c), but also soft terms such as "algorithm" appear (Figure 14d). The yellow cluster includes terms related to new building materials or materials to change the envelope behavior, such as "phase change material" (Figure 14e). Finally, the purple cluster includes technologies used in buildings for heating and cooling, such as "solar energy," "geothermal energy," and "heat pump" (Figure 14e). Nevertheless, renewables are not as prominent as might be expected. 


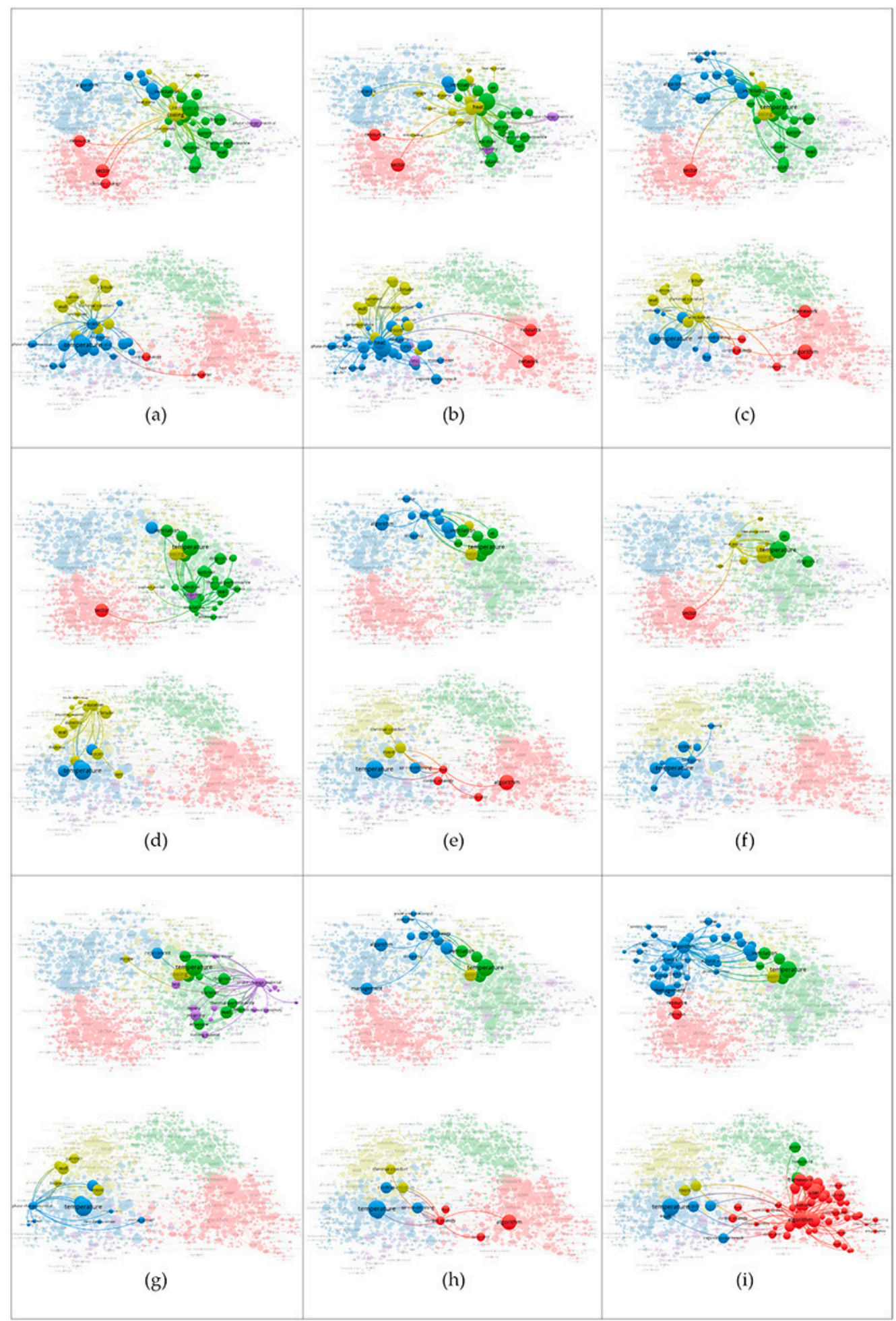

Figure 14. Detail of the co-occurrence keywords (left: Web of Science, and right: Scopus): (a) links of the term "cooling"; (b) links of the term "heating"; (c) links of the term "ventilation"; (d) links of the term "insulation"; (e) links of the terms "HVAC" and "HVAC system"; (f) links of the term "heat pump"; (g) links of the term "phase change material"; (h) links of the term "control strategies"; and (i) links of the term "algorithm".

The term "cooling" is related to "ventilation" and "thermal comfort" as well as to "summer." However, it is also related to terms associated with the building envelope. It is also linked to "control 
strategies" and "algorithm." On the other hand, "heating" is mostly only related to technologies associated with the building envelop, such as "phase change material," "wall," and "insulation." As expected, the term "ventilation" is related to "wall" and "window," as well as to "cooling" and "air conditioning." However, it is also related to "control strategy," "algorithm," "controller," and "model predictive control," since ventilation technologies improve with the use of advanced control strategies. "Insulation" is mostly related to "wall" and "thermal performance," as well as to "thickness," "insulation material," and "property." The term "HVAC" has fewer links. It is mostly related to "cooling," "ventilation," and air conditioning," since it is a technology used for such strategies and to "control strategy," "controller," and "algorithm," since research on control strategies is widely applied to HVAC technologies. Similarly, "heat pump" is linked to "cooling" and "air conditioning" but not so much to control strategies terms. As expected, "heat pump" is also linked to "space heating." "Phase change material" is a term that appears widely in the recent literature, linked to all terms related to "wall," "envelope," and "room", and also to "energy storage" and "thermal performance." Finally, this term has strong links to "property."

Figure 14 also shows that "control strategy" is one of the terms related to novel soft technologies. As expected, it is linked with "controller" and "algorithm" but also to "model predictive control." On the other hand, it is linked to terms related with the technologies where it is applied, such as "thermal comfort," "air conditioning," "cooling," and "ventilation". The last highlighted term is "algorithm," which is also related to new soft technologies, and appears prominently in the network map and is highly related to many other terms.

\section{Conclusions}

The publications concerning energy efficiency and carbon mitigation from buildings within the international scientific knowledge since year 2013 were assessed with a bibliometric analysis using Web of Science and Scopus databases as the sources. Overall, 17,468 publications were found with WoS and 19,416 with Scopus, and only $11 \%$ of the documents were common to both databases. Most of them fell within the area of Engineering and Energy Fuels, which is specially covered in Scopus; $94.2 \%$ of the documents in WoS and 98.6\% in Scopus are in English. The databases differ most on the number of documents in Chinese and Japanese, which are more abundant in Scopus; Spanish and German documents are very common and equally found in both databases. The databases have different analytical features, e.g., only WoS database provides metrics related to the country and journals or the authors' institutional affiliation, although in turn only the Scopus database provides keywords. On the other hand, both databases showed a peak of published documents in 2017 and represented the same countries working on the topic, even when the publications per capita were compared for both databases. Finally, evaluating the co-occurrence of keywords using VOSviewer also gave very similar results for both databases. In all, we identified differences in the content of the databases, which suggests that future research should be informed from both Scopus and WoS.

The growth within the period studied was steady. Most publications were scientific papers/articles in English, and the journal with the highest amount of publications was Energy and Buildings. Among these publications, the contributions from China and the USA were the largest. Additionally, the institutes that contributed the largest number of publications were not only from China and the USA but also from France and Italy. A similar pattern was found for the authors with the most publications because four of them were from China or the USA, but the others were from Spain, Italy, and Canada. Links were found among the most published authors showing strong international collaboration in the topic of study.

The analysis of the keywords shows a balanced interest on varying subsectors and typologies, which includes new and existing buildings, as well as the residential and services sectors. A major segment of the research during this time period focused on energy issues (efficiency, conservation, management, consumption) and in technologies for heating, ventilation, and air-conditioning, phase change materials, and information and communication technologies. A significantly smaller segment of the literature 
takes a broader perspective (greenhouse gas emissions, life cycle, sustainable development), and investigates implementation issues (policies and costs) or renewable energy (solar). Nevertheless, our analysis also shows that, although the terms climate change and greenhouse gas emissions are among the most common keywords, many researchers working on technologies for energy efficiency of buildings do not associate their research with those concepts (Figure 15). Knowledge gaps are detected in the areas of behavioral changes and non-technological measures, the circular economy, and some renewable energy sources (geothermal, biomass, small wind). We recommend that future research focuses on filling the above identified gaps, including extending energy analyses to their effects in terms of mitigation potentials. These conclusions should be validated with further analyses at full text level of the documents identified in this study.
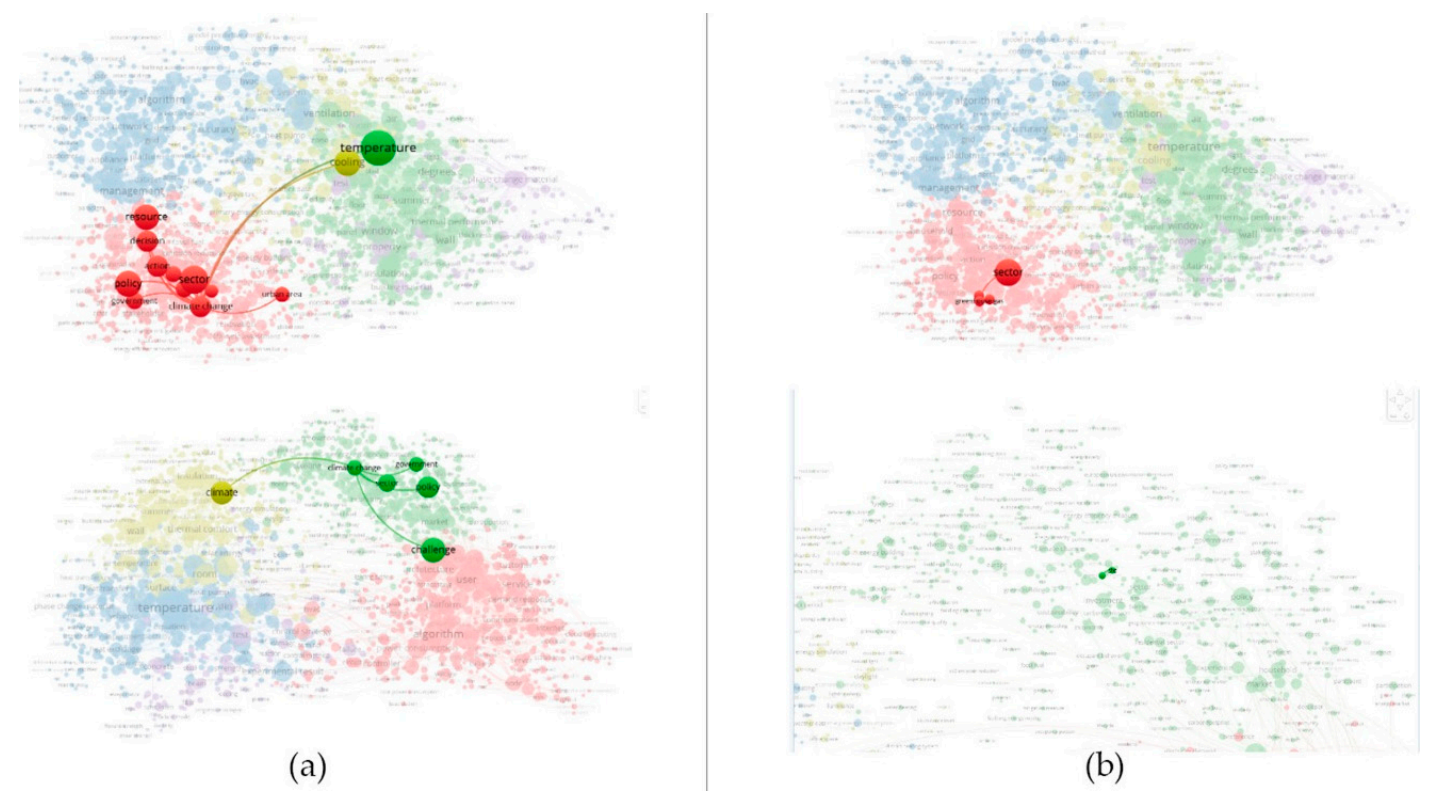

Figure 15. Detail of the co-occurrence of keywords (left: Web of Science, and right: Scopus): (a) links of the term "climate change"; (b) links of the terms "greenhouse gas", "greenhouse gases", and "greenhouse gas emissions".

Author Contributions: Conceptualization, L.F.C. and É.M.; methodology, L.F.C., É.M., and M.C.; investigation, L.F.C. and M.C.; writing-original draft preparation, M.C.; writing-review and editing, L.F.C. and É.M.; visualization, L.F.C. and M.C.; project administration, L.F.C.; funding acquisition, L.F.C. and É.M. All authors have read and agreed to the published version of the manuscript.

Funding: This work was funded by the Ministerio de Ciencia, Innovación y Universidades de España (RTI2018-093849-B-C31), by ICREA under the ICREA Academia programme, and by the foundation SIVL.

Acknowledgments: The authors would like to thank the Catalan Government for the quality accreditation given to their research group (2017 SGR 1537). GREiA is a certified TECNIO agent in the category of technology developers from the Government of Catalonia.

Conflicts of Interest: The authors declare no conflict of interest.

\section{References}

1. $\quad$ Lucon, O.D.; Ürge-Vorsatz, A.; Zain Ahmed, H.; Akbari, P.; Bertoldi, L.F.; Cabeza, N.; Eyre, A.; Gadgil, L.D.D.; Harvey, Y.; Jiang, E.; et al. Buildings. In Climate Change 2014: Mitigation of Climate Change, Contribution of Working Group III to the Fifth Assessment Report of the Intergovernmental Panel on Climate Change; Edenhofer, O.R., Pichs-Madruga, Y., Sokona, E., Farahani, S., Kadner, K., Seyboth, A., Adler, I., Baum, S., Brunner, P., Eickemeier, B., et al., Eds.; Cambridge University Press: Cambridge, UK; New York, NY, USA, 2014; pp. 639-706. 
2. Minx, J.C.; Callaghan, M.; Lamb, W.F.; Garard, J.; Edenhofer, O. Learning about climate change solutions in the IPCC and beyond. Environ. Sci. Policy 2017, 77, 252-259. [CrossRef]

3. Sutherland, W.J.; Wordley, C.F.R. A fresh approach to evidence synthesis. Nature 2018, 558, $364-366$. [CrossRef] [PubMed]

4. Donnelly, C.; Boyd, I.; Campbell, P.; Craig, C.; Vallance, P.; Walport, M.; Whitty, C.; Woods, E.; Wormald, C. Four principles for synthesizing evidence. Nature 2018, 558, 361-364. [CrossRef] [PubMed]

5. Haddaway, N.R.; Macura, B. The role of reporting standards in producing robust literature reviews. Nat. Clim. Chang. 2018, 8, 444-447. [CrossRef]

6. Belter, C.W.; Seidel, D.J. A bibliometric analysis of climate engineering research. Wiley Interdiscip. Rev. Clim. Chang. 2013, 4, 417-427. [CrossRef]

7. Hicks, D.; Wouters, P.; Waltman, L.; De Rijcke, S.; Rafols, I. Bibliometrics: The Leiden Manifesto for research metrics. Nature 2015, 520, 429-431. [CrossRef]

8. Li, J.; Hou, Y.; Wang, P.; Yang, B. A Review of carbon capture and storage project investment and operational decision-making based on bibliometrics. Energies 2019, 12, 23. [CrossRef]

9. Harzing, A.W.K.; van der Wal, R. Google Scholar as a new source for citation analysis. Ethics Sci. Environ. Polit. 2008, 8, 61-73. [CrossRef]

10. Harzing, A.W.; Alakangas, S. Google Scholar, Scopus and the Web of Science: A longitudinal and cross-disciplinary comparison. Scientometrics 2016, 106, 787-804. [CrossRef]

11. Aguillo, I.F. Is Google Scholar useful for bibliometrics? A webometric analysis. Scientometrics 2012, 91, 343-351. [CrossRef]

12. Aghaei Chadegani, A.; Salehi, H.; Md Yunus, M.M.; Farhadi, H.; Fooladi, M.; Farhadi, M.; Ale Ebrahim, N. A comparison between two main academic literature collections: Web of science and Scopus databases. Asian Soc. Sci. 2013, 9, 18-26. [CrossRef]

13. Falagas, M.E.; Pitsouni, E.I.; Malietzis, G.A.; Pappas, G. Comparison of PubMed, Scopus, Web of Science, and Google Scholar: Strengths and weaknesses. FASEB J. 2008, 22, 338-342. [CrossRef] [PubMed]

14. Vieira, E.S.; Gomes, J.A.N.F. A comparison of Scopus and Web of science for a typical university. Scientometrics 2009, 81, 587-600. [CrossRef]

15. Archambault, É.; Campbell, D.; Gingras, Y.; Vincent, L. Comparing bibliometric statistics obtained from the web of Science and Scopus. J. Am. Soc. Inf. Sci. Technol. 2009, 60, 1320-1326. [CrossRef]

16. Mongeon, P.; Paul-Hus, A. The journal coverage of Web of Science and Scopus: A comparative analysis. Scientometrics 2016, 106, 213-228. [CrossRef]

17. Jacso, P. As we may search-Comparison of major features of the Web of Science, Scopus, and Google Scholar citation-based and citation-enhanced databases. Curr. Sci. 2005, 89, 1537-1547.

18. Falagas, M.E.; Kouranos, V.D.; Arencibia-Jorge, R.; Karageorgopoulos, D.E. Comparison of SCImago journal rank indicator with journal impact factor. FASEB J. 2008, 22, 2623-2628. [CrossRef]

19. Uribe-Toril, J.; Ruiz-Real, J.L.; Milán-García, J.; Valenciano, J.D.P. Energy, economy, and environment: Aworldwide research update. Energies 2019, 12, 1120. [CrossRef]

20. Wuni, I.Y.; Shen, G.Q.P.; Osei-Kyei, R. Scientometric review of global research trends on green buildings in construction journals from 1992 to 2018. Energy Build. 2019, 190, 69-85. [CrossRef]

21. Pera-Moreno, M.A.; Hernandez-Escobedo, Q.; Perea-Moreno, A.J. Renewable energy in urban areas: Worldwide research trends. Energies 2018, 11, 577. [CrossRef]

22. De la Cruz-Lovera, C.; Perea-Moreno, A.J.; de la Cruz-Fernández, J.L.; Alvarez-Bermejo, J.A.; Manzano-Agugliaro, F. Worldwide research on energy efficiency and sustainability in public buildings. Sustainability 2017, 9, 1294. [CrossRef]

23. De La Cruz-Lovera, C.; Perea-Moreno, A.J.; De La Cruz-Fernandez, J.L.; Montoya, F.G.; Alcayde, A.; Manzano-Agugliaro, F. Analysis of research topics and scientific collaborations in energy saving using bibliometric techniques and community detection. Energies 2019, 12, 2030. [CrossRef]

24. Morkūnaitè, Ž.; Kalibatas, D.; Kalibatienè, D. A bibliometric data analysis of multi-criteria decision making methods in heritage buildings. J. Civ. Eng. Manag. 2019, 25, 76-99. [CrossRef]

25. Zhao, X.; Zuo, J.; Wu, G.; Huang, C. A bibliometric review of green building research 2000-2016. Archit. Sci. Rev. 2019, 62, 74-88. [CrossRef]

26. Trianni, A.; Merigó, J.M.; Bertoldi, P. Ten years of Energy Efficiency: A bibliometric analysis. Energy Effic. 2018, 11, 1917-1939. [CrossRef] 
27. Camarasa, C.; Nägeli, C.; Ostermeyer, Y.; Klippel, M.; Botzler, S. Diffusion of energy efficiency technologies in European residential buildings: A bibliometric analysis. Energy Build. 2019, 202, 109339. [CrossRef]

28. Díaz-López, C.; Carpio, M.; Martín-Morales, M.; Zamorano, M. Analysis of the scientific evolution of sustainable building assessment methods. Sustain. Cities Soc. 2019, 49, 101610. [CrossRef]

29. Van Eck, N.J.; Waltman, L. Software survey: VOSviewer, a computer program for bibliometric mapping. Scientometrics 2010, 84, 523-538. [CrossRef]

30. Kamdem, J.P.; Duarte, A.E.; Lima, K.R.R.; Rocha, J.B.T.; Hassan, W.; Barros, L.M.; Roeder, T.; Tsopmo, A. Research trends in food chemistry: A bibliometric review of its 40 years anniversary (1976-2016). Food Chem. 2019, 294, 448-457. [CrossRef]

31. Shukla, A.K.; Janmaijaya, M.; Abraham, A.; Muhuri, P.K. Engineering applications of artificial intelligence: A bibliometric analysis of 30 years (1988-2018). Eng. Appl. Artif. Intell. 2019, 85, 517-532. [CrossRef]

32. Moral-Munoz, J.A.; Carballo-Costa, L.; Herrera-Viedma, E.; Cobo, M.J. Production trends, collaboration, and main topics of the integrative and complementary oncology research area: A bibliometric analysis. Integr. Cancer Ther. 2019, 18, 1534735419846401. [CrossRef] [PubMed]

33. Galagoda, R.U.; Jayasinghe, G.Y.; Halwatura, R.U.; Rupasinghe, H.T. The impact of urban green infrastructure as a sustainable approach towards tropical micro-climatic changes and human thermal comfort. Urban For. Urban Green. 2018, 34, 1-9. [CrossRef]

34. Yeung, A.W.K.; Goto, T.K.; Leung, W.K. The changing landscape of neuroscience research, 2006-2015: A bibliometric study. Front. Neurosci. 2017, 11, 2006-2015. [CrossRef] [PubMed]

35. Van Eck, N.J.; Waltman, L. Citation-based clustering of publications using CitNetExplorer and VOSviewer. Scientometrics 2017, 111, 1053-1070. [CrossRef]

36. Perianes-Rodriguez, A.; Waltman, L.; van Eck, N.J. Constructing bibliometric networks: A comparison between full and fractional counting. J. Informetr. 2016, 10, 1178-1195. [CrossRef]

37. United Nations, Department of Economic and Social Affairs, Population Division. World Population Prospects: The 2010 Revision, CD-ROM Edition; UN DESA: New York, NY, USA, 2011.

38. Cabeza, L.F.; Chafer, M. Technological options and strategies towards zero energy buildings contributing to climate change mitigation: Systematic review. 2020; Unpublished work.

(C) 2020 by the authors. Licensee MDPI, Basel, Switzerland. This article is an open access article distributed under the terms and conditions of the Creative Commons Attribution (CC BY) license (http://creativecommons.org/licenses/by/4.0/). 